\title{
Ric-8a, a Guanine Nucleotide Exchange Factor for Heterotrimeric G Proteins, Regulates Bergmann Glia-Basement Membrane Adhesion during Cerebellar Foliation
}

\author{
Shang Ma, ${ }^{1,2}$ Hyo Jun Kwon, ${ }^{1,3}$ and Zhen Huang ${ }^{1}$ \\ ${ }^{1}$ Departments of Neurology and Neuroscience, ${ }^{2}$ Graduate Program in Cellular and Molecular Biology, and ${ }^{3}$ Neuroscience Training Program, University of \\ Wisconsin-Madison, Madison, Wisconsin 53706
}

\begin{abstract}
The cerebellum consists of an intricate array of lobules that arises during the process of foliation. Foliation not only increases surface area, but may also facilitate organization of cerebellar neural circuitry. Defects in cerebellar foliation are associated with a number of diseases. Yet, little is known about how foliation, a process involving large-scale and simultaneous movement of several different cell types, is coordinated by cell-cell signaling at the molecular level. Here we show that Ric-8a, a guanine nucleotide exchange factor in the G-proteincoupled receptor pathway, is specifically required in Bergmann glia during cerebellar foliation. We find that ric-8a mutation in mice results in disorganized Bergmann glial scaffolding, defective granule cell migration, and disrupted Purkinje cell positioning. These abnormalities result from primary defects in Bergmann glia since mutations in granule cells do not show similar effects. They first arise during late embryogenesis, at the onset of foliation, when ric- $8 a$ mutant Bergmann glia fail to maintain adhesion to the basement membrane specifically at emerging fissures. This suggests that Ric-8a is essential for the enhanced Bergmann glia-basement membrane adhesion required for fissure formation. Indeed, we find that ric-8a-deficient cerebellar glia show decreased affinity for basement membrane components. We also find that weakening Bergmann glia-basement membrane interaction by $\beta 1$ integrin deletion results in a similar phenotype. These results thus reveal a novel role of Ric-8a in modulating Bergmann glia-basement membrane adhesion during foliation, and provide new insights into the signaling pathways that coordinate cellular movement during cerebellar morphogenesis.
\end{abstract}

\section{Introduction}

The cerebellum is composed of distinct layers including the molecular, the Purkinje, and Bergmann glial cell body, as well as the granule cell layers. This laminar organization arises during development in a complex morphogenetic process, where granule cell precursors migrate from the external to the internal layer, while at the same time driving the formation of cerebellar folia (Sillitoe and Joyner, 2007). Studies have shown that granule cell precursor proliferation, induced by Purkinje cell-secreted Sonic hedgehog (Dahmane and Ruiz i Altaba, 1999; Wallace, 1999; WechslerReya and Scott, 1999; Corrales et al., 2004; Lewis et al., 2004), is the main driving force behind cerebellar foliation. Increased Sonic hedgehog signaling leads to a more complex foliation pattern, while decreased signaling results in a simplified pattern

\footnotetext{
Received March 15, 2012; revised Aug. 20, 2012; accepted Aug. 25, 2012.

Author contributions: S.M. and Z.H. designed research;S.M., H.J.K., and Z.H. performed research;S.M., H.J.K., and Z.H. analyzed data; Z.H. wrote the paper.

This work was supported by startup funds from University of Wisconsin-Madison, a Basil O'Connor Starter Investigator award from the March of Dimes foundation, and a grant from the Graduate School Research Committee of University of Wisconsin-Madison. Z.H. thanks Dr. Louis. F. Reichardt (University of California San Francisco) for supporting the initial generation of ric-8a conditional mutant ES cells.

Correspondence should be addressed to Zhen Huang, Departments of Neurology and Neuroscience, University of Wisconsin-Madison, Madison, Wisconsin 53706. E-mail: z.huang@neurology.wisc.edu.

DOI:10.1523/JNEUROSCI.1282-12.2012

Copyright $\odot 2012$ the authors $\quad 0270-6474 / 12 / 3214979-15 \$ 15.00 / 0$
}

(Corrales et al., 2006). On the other hand, Bergmann glia appear to play a more direct role in the physical reorganization of cerebellar cell types (Sudarov and Joyner, 2007). When Bergmann glia are absent, fissures fail to form (Hoser et al., 2007). When the glial scaffold is disrupted, lobules are frequently fused and granule cell migration is compromised (Delaney et al., 1996; GrausPorta et al., 2001; Qu and Smith, 2005; Yue et al., 2005; Belvindrah et al., 2006; Mills et al., 2006; Qiu et al., 2010). These defects are frequently associated with deficiencies in a key function provided by Bergmann glia, i.e., the retention, assembly, and/or maintenance of basement membrane along the length of invaginating fissures as well as on the external surface. Thus, Bergmann glia-basement membrane interaction is critical for many aspects of cerebellar development. Yet, little is known about how this interaction is modulated and coordinated with other cellular events.

The G-protein-coupled receptor (GPCR) pathway is a key signaling pathway regulating many developmental and physiological processes (Marinissen and Gutkind, 2001; Malbon, 2005). In the immune system, chemokine-GPCR signaling is known to regulate substrate interaction by several cell types (Kinashi, 2005), including sustained adhesion by progenitor B cells to the bone marrow microenvironment (Le et al., 2007), as well as attachment of leukocytes to the endothelium during their migra- 
tion into tissues (Shamri et al., 2005). These similarities raise the possibility that GPCR signaling may play a role in modulating Bergmann glia-basement membrane interaction. In the nervous system, although not yet directly implicated in cell-substrate interaction, GPCR signaling regulates the targeting of several migrating neural cell types (Tsai et al., 2002; Borrell and Marin, 2006; Li et al., 2008; López-Bendito et al., 2008). These findings point to a potential role of GPCR signaling in Bergmann gliabasement membrane interaction. However, GPCR signaling is mediated by several classes of heterotrimeric $G$ proteins, including $21 \mathrm{G} \alpha, 6 \mathrm{G} \beta$, and $12 \mathrm{G} \gamma$ subunits in mouse. This poses a problem of genetic redundancy. To circumvent this, we focus in this study on Ric-8a, a nonreceptor guanine nucleotide exchange factor that regulates several $\mathrm{G} \alpha$ subunits, including $\mathrm{G} \alpha \mathrm{i}, \mathrm{G} \alpha \mathrm{o}$, and G $\alpha \mathrm{q}$ (Miller et al., 2000; Tall et al., 2003; Tall and Gilman, 2005), and investigate the role of GPCR signaling in cerebellar development.

\section{Materials and Methods}

Mouse breeding and pharmacological treatment. ric-8a conditional allele was generated by floxing exons $2-4$ (to be published elsewhere). $\beta 1$ integrin conditional allele was as published (Graus-Porta et al., 2001; Huang et al., 2006). hGFAP-cre was a kind gift from Dr. Albee Messing (University of Wisconsin-Madison) (Zhuo et al., 2001). nestin-cre (Stock\# 003771), nestin-creER (Stock\# 012906), math1-creERT2 (Stock\# 007684), pcp2-cre (Stock\# 006207), and mTomato/mEGFP reporter (Stock\# 007576) lines were purchased from The Jackson Laboratory. hGFAP-cre, nestin-cre, math1-creERT2, or pcp2-cre were introduced into the ric-8a conditional mutant background for phenotypic analyses and ric- $8 a$ homozygotes without $c r e$ as well as heterozygotes with cre were both analyzed as controls. Similarly, nestin-creER was introduced into the $\beta 1$ integrin conditional mutant background for phenotypic analyses. Animals analyzed were of either sex and were in the mixed background of FVB, 129, and C57BL6. However, despite a mixed background, we observed a highly consistent foliation pattern in all control animals. Two and three milligrams of tamoxifen, respectively, was administered by intraperitoneal injection at embryonic day 15.5 (E15.5) for ric-8a/math1creERT2 crosses, and at E18.0 for $\beta 1 /$ nestin-creER crosses. Noon after vaginal plug is regarded as E0.5, and day of birth as P0. For S-phase labeling, 5-bomodeoxyuridine (BrdU) was injected at $100 \mu \mathrm{g} / \mathrm{gbw}$ (gram of body weight) and brains were harvested $4 \mathrm{~h}$ later for fixation and processing. Animal use was in accordance with institutional guidelines.

Immunohistochemistry. The following primary antibodies were used at respective dilutions: mouse anti-BrdU supernatant (clone G3G4; Developmental Studies Hybridoma Bank [DSHB]), University of Iowa; 1:40), mouse anti-Nestin supernatant (1:20; DSHB), mouse anti-Math1 (1: 10; DSHB), mouse anti-NeuN (clone A60; Millipore, 1:250), mouse antiPax6 supernatant (1:20; DSHB), mouse anti-glial fibrillary acid protein (GFAP; NeuroMab, 1:400), rat anti- $\beta 1$ integrin (clone MB1.2, 1: 100), rabbit anti-phospho Histone H3 (Ser10) (1:400; Millipore), rabbit antiCalbindin (1:400; GenScript), rabbit anti-collagen IV (AbD; Serotec, 1:500), rabbit anti-Laminin (1:2000; Sigma), mouse anti-Tubulin $\beta 3$ (TuJ1) (1:500; Covance), rabbit anti-brain lipid binding protein (BLBP; 1:500; Millipore), and rabbit anti-Ric-8a (1:4000; Novatein). Fluorescein isothiocyanate- and Cy3-conjugated secondary antibodies were purchased from Jackson ImmunoResearch Laboratories. Peroxidaseconjugated secondary antibodies were purchased from Santa Cruz Biotechnology. Staining procedures were performed as described previously (Huang et al., 2006), except for anti-Ric-8a staining (see below), and sections were mounted with Fluoromount-G medium (Southern Biotech). Stained sections were analyzed under a Nikon eclipse Ti microscope at room temperature using the NIS-Elements BR 3.0 software. The same exposure conditions were used for analyzing controls and mutants. For Ric-8a staining, antibody incubation and wash were done in solutions containing $0.3 \%$ Saponin instead of $0.4 \%$ Triton X-100 and followed by the use of a tyramide signal amplification Cy3 kit (PerkinElmer).
Western blotting and reverse transcription-PCR. Standard Western blotting procedures were performed using a Bio-Rad electrophoresis and transfer apparatus. An anti- $\beta$-tubulin monoclonal antibody (E7; DSHB) was used as control for protein loading. Total RNA was isolated using a Total RNA Isolation kit from Promega, and cDNA was synthesized using a Vero cDNA kit (Thermo Scientific). Intron spanning primer pairs were used for PCR. These are as follows: $\beta$-actin ( $5^{\prime}$ tgaaccctaaggccaaccgtg $3^{\prime}, 5^{\prime}$ gctcatagctcttctc caggg $\left.3^{\prime}\right)$ and ric-8a (5'gcactgcgtgatggttgaagc $3^{\prime}, 5^{\prime}$ gcacattctgtcaacacgttca $\left.3^{\prime}\right)$.

Cell adhesion assay. P6 cerebella were dissected in cold $1 \times$ Dulbecco's PBS (DPBS) (Meditech) and incubated for $5 \mathrm{~min}$ at $37^{\circ} \mathrm{C}$ in $100 \mu \mathrm{l}$ of HBSS (Meditech) containing $1 \mathrm{mg} / \mathrm{ml}$ DNase, and 0.5\% trypsin. Then $800 \mu \mathrm{l}$ DMEM (Invitrogen) containing 10\% fetal bovine serum (FBS) (Sigma) was added and cells were mechanically dissociated. For acutely dissociated cell adhesion assay, 50,000 cells per well were incubated in DMEM $+10 \%$ FBS on coverslips precoated with $2 \mu \mathrm{g} / \mathrm{ml}$ laminin or 2 $\mu \mathrm{g} / \mathrm{ml}$ poly-D-lysine. For glia-enriched adhesion assay, $3 \times 10^{6}$ resuspended cells were cultured for $2 \mathrm{~d}$ in DMEM $+10 \%$ FBS in plastic wells precoated with both $10 \mu \mathrm{g} / \mathrm{ml}$ laminin and $10 \mu \mathrm{g} / \mathrm{ml}$ poly-D-lysine. DPBS $(1 \times)$ containing $0.25 \%$ trypsin was used to rinse off attached cells, which were then resuspended in DMEM $+10 \%$ FBS and incubated $(50,000$ cells per well) overnight on coverslips precoated with $2 \mu \mathrm{g} / \mathrm{ml} \mathrm{laminin} \mathrm{or}$ $2 \mu \mathrm{g} / \mathrm{ml}$ poly-D-lysine. For $1 \mathrm{~h}$ adhesion assay, acutely dissociated cells were resuspended with DMEM $+10 \%$ FBS. For $1 \mathrm{~h}$ at $37^{\circ} \mathrm{C}, 400,000$ cells per well were plated on 8-well Tek chamber slides (Thermo Scientific) precoated with $2 \mu \mathrm{g} / \mathrm{ml}$ laminin or poly-D-lysine. For all assays, unbound cells were rinsed off gently with DPBS and adherent cells were fixed with $4 \%$ paraformaldehyde for $5 \mathrm{~min}$ on ice, followed by immunocytochemistry. For quantitative analysis, images from 20 to 25 randomly selected fields were collected from each sample to minimize potential variation in substrate coating.

Quantification and statistical analysis. Immunopositive cells, captured under the same exposure conditions for control and mutant sections, were counted manually using the NIS-Elements BR 3.0 software from Nikon. Statistical analysis was performed using Student's $t$ test. Values are given as mean \pm SEM.

\section{Results}

Deletion of ric-8a by $h$ GFAP-cre results in severe cerebellar malformation

In the cerebellum, ric- $8 a$ is widely expressed in the molecular and granule cell layers as well as in the Bergmann glial and Purkinje cell bodies located between these layers (Tõnissoo et al., 2003; Lein et al., 2007) (Fig. 1I,J). Since conventional mutations in ric-8a result in early embryonic lethality (Tõnissoo et al., 2006, 2010), to determine the in vivo function of ric- $8 a$, we used a conditional allele of ric- $8 a$ (to be published elsewhere), in which exons $2-4$ are flanked by a pair of loxP sites. To delete ric- $8 a$, we used an $h G F A P$-cre that targets neural progenitors as well as astroglia throughout the nervous system (Zhuo et al., 2001; Malatesta et al., 2003). To evaluate patterns of $h G F A P$-cre activity, we introduced, into the $h G F A P$-cre transgenic background, an $m T o$ mato/mEGFP dual fluorescent cre reporter (Muzumdar et al., 2007), which expresses mTomato before, and mEGFP after, creinduced recombination. We found that hGFAP-cre-induced widespread recombination throughout the cerebellum (Fig. $1 \mathrm{~A}-$ $D)$. At postnatal day 21 (P21), strong $m E G F P$ expression was observed in the molecular layer while moderate $m E G F P$ expression was detected in the granule cell layer (Fig. $1 A, E$ ). On the other hand, strong $m$ Tomato continued to be expressed in nonneural cell types including vascular endothelial cells and meningeal fibroblasts (Fig. $1 B, F$ ). Thus, $h G F A P$-cre specifically targets neural cell types in the cerebellum.

To determine effects of ric-8a deletion on cerebellar development, we next introduced the hGFAP-cre transgene into the ric- 8 a conditional mutant background. We first examined effects of gene deletion on Ric-8a protein expression at P5. In controls at 

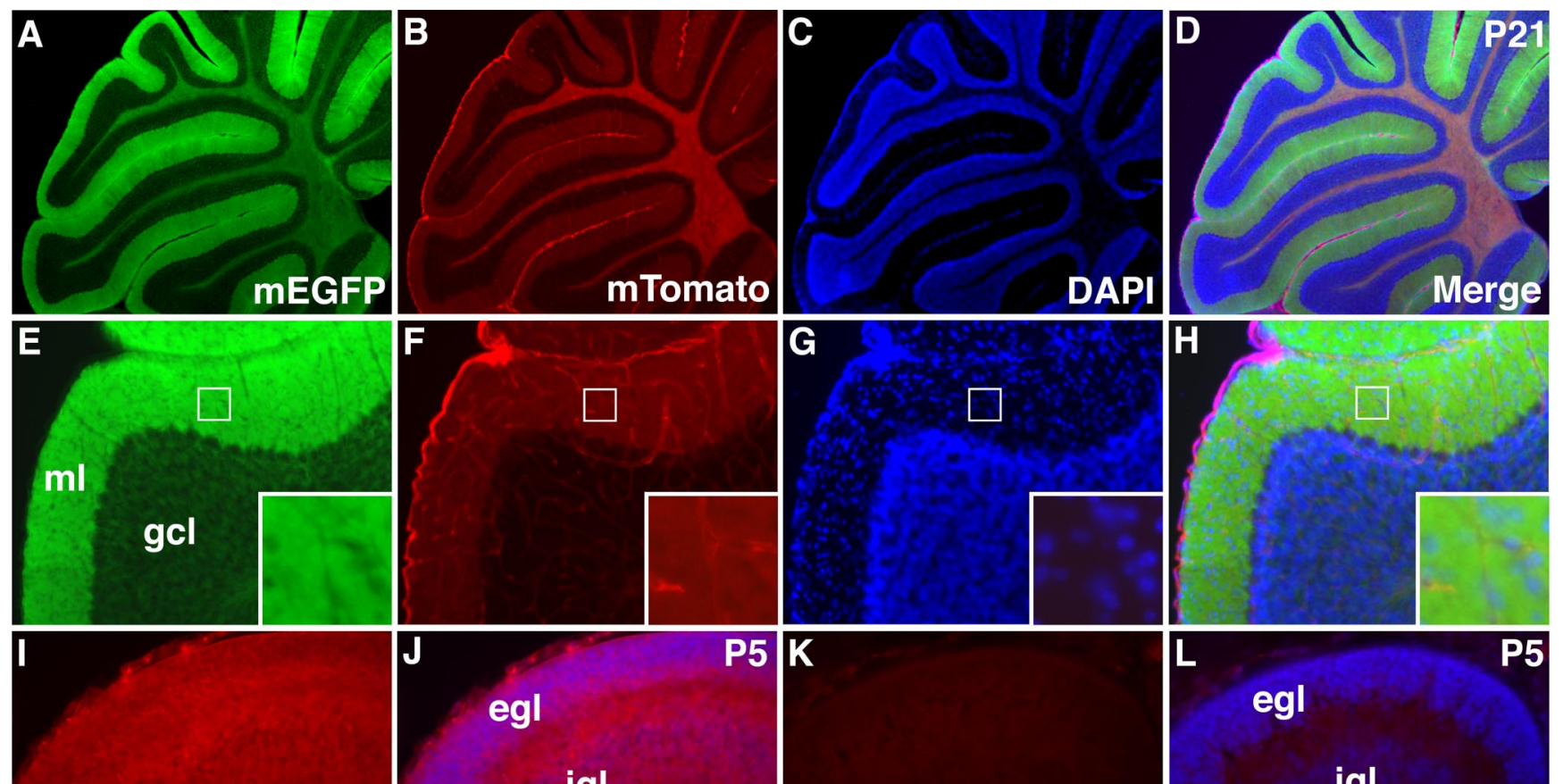

igl

igl

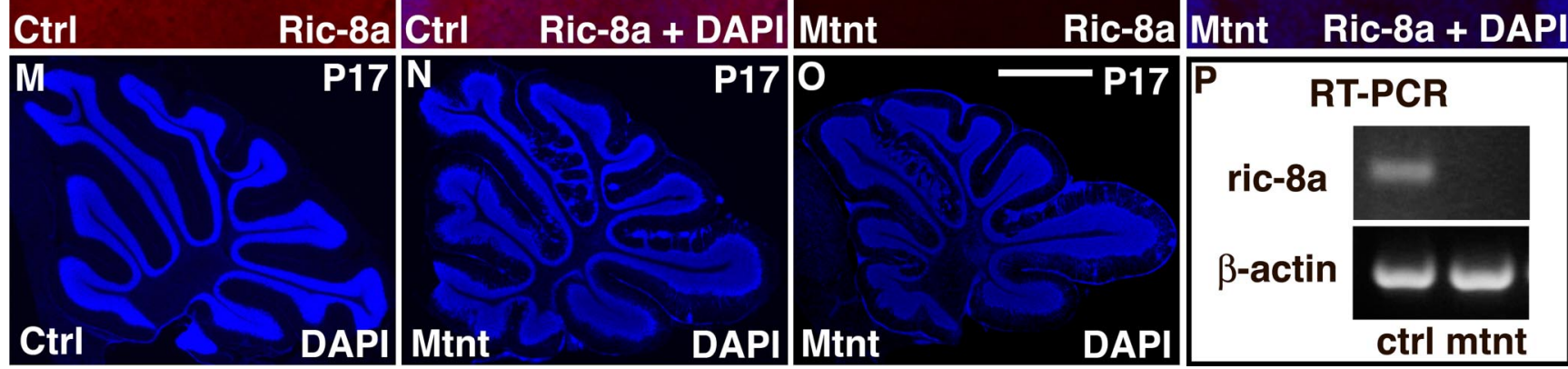

Figure 1. hGFAP-cre-mediated deletion of ric-8a results in cerebellar malformation. $\boldsymbol{A}-\boldsymbol{H}$, Patterns of $h$ GFAP-cre-induced recombination at P21 as determined using an $m$ Tomato/mEGFPreporter, which expresses mTomato before and mEGFP after cre-induced recombination. Strong mEGFP expression is observed in the molecular layer $(\boldsymbol{A}, \boldsymbol{E})$, while strong $m$ Tomato expression remains in the meninges $(\boldsymbol{B}, \boldsymbol{F})$. Overall cerebellar morphology is determined by DAPI staining $(\boldsymbol{C}, \boldsymbol{G})$. Examination at higher magnifications showed that the strong mEGFP expression in the molecular layer likely resides in both cell bodies and neuronal processes, while blood vessels express mTomato ( $\boldsymbol{E}, \boldsymbol{H}$, and insets). Moderate levels of mEGFP expression are also observed in the granule cell layer. $\boldsymbol{I}-\boldsymbol{L}$, Loss of Ric-8a protein from ric-8a/hGFAP-cre mutant cerebella. In controls at P5, Ric-8a protein is expressed more or less uniformly across different cerebellar layers, including the external granule cell layer and internal granule cell layers as well as the Purkinje and Bergmann glial cell body layers located between these layers $(I, J)$. In contrast, no significant Ric-8a immunoreactivity is observed in mutants $(\boldsymbol{K}, \boldsymbol{L})$. $\boldsymbol{M}-\boldsymbol{P}$, Defective cerebellar foliation and granule cell migration in ric-8a/hGFAP-cre mutants at P17. In contrast to the littermate control ( $\boldsymbol{M})$, folial morphology is disrupted across the entire cerebellar section, especially surrounding the primary and secondary fissures, in ric-8a mutants $(\boldsymbol{N}, \mathbf{0})$. Many ectopic granule cells (in blue, DAPI staining) are also trapped in either the EGL or the molecular layer. reverse transcription-PCR confirms that ric-8a mRNA is lost from cerebellar tissues following gene deletion (P). Scale bar: $\boldsymbol{O}$ (for $\boldsymbol{A}-\boldsymbol{D}), 500 \mu \mathrm{m}$; (for $\boldsymbol{E}-\boldsymbol{K}$ ), $100 \mu \mathrm{m}$; and (for M-0), $1 \mathrm{~mm}$. ml, Molecular layer; gcl, granule cell layer; egl, external granule layer; igl, internal granule layer.

P5, we observed strong Ric-8a immunoreactivity in all layers of the cerebellum (Fig. $1 I, J$ ), including the external and internal granule layers as well as the Bergmann glial and Purkinje cell bodies located between these layers. In contrast, minimal Ric-8a immunoreactivity was observed in mutants at the same stage (Fig. $1 K, L)$. Similar differences were also observed between controls and mutants at P0 (data not shown). Thus, these results indicate that $h G F A P$-cre induces efficient $r i c-8 a$ gene deletion and that this results in widespread loss of Ric- 8 a protein from an early stage. Next, we examined the effects of ric- $8 a$ deletion on the mutant mice. At P17, the latest stage to which they survived, ric-8a/hGFAP-cre mutant animals showed obvious ataxia, suggesting defects in cerebellar development and function. Indeed, anatomical analysis showed that mutant cerebella were severely disorganized (Fig. 1, compare $M, N, O$ ). Although the overall folial pattern appeared more or less normal, nearly all lobules showed obvious morphological defects. Granule cell migration from the external to the internal granule layer was also perturbed in most lobules, especially in lobules surrounding the primary and secondary fissures. Thus, these results indicate that ric- $8 a$ plays an essential role in cerebellar development.

To further evaluate ric- $8 a$ mutant phenotype, we next used several antibodies to examine the various cerebellar neural cell types as well as the basement membrane. First, we used antibodies against GFAP and collagen IV to examine the Bergmann glia and basement membrane, respectively. In the control cerebellum at P17 (Fig. 2A-D), along all fissures, we found Bergmann glial fibers consistently form a well organized parallel scaffold anchored through their endfeet at the basement membrane (Fig. $2 B-D)$. Granule cells had also largely finished their internal mi- 


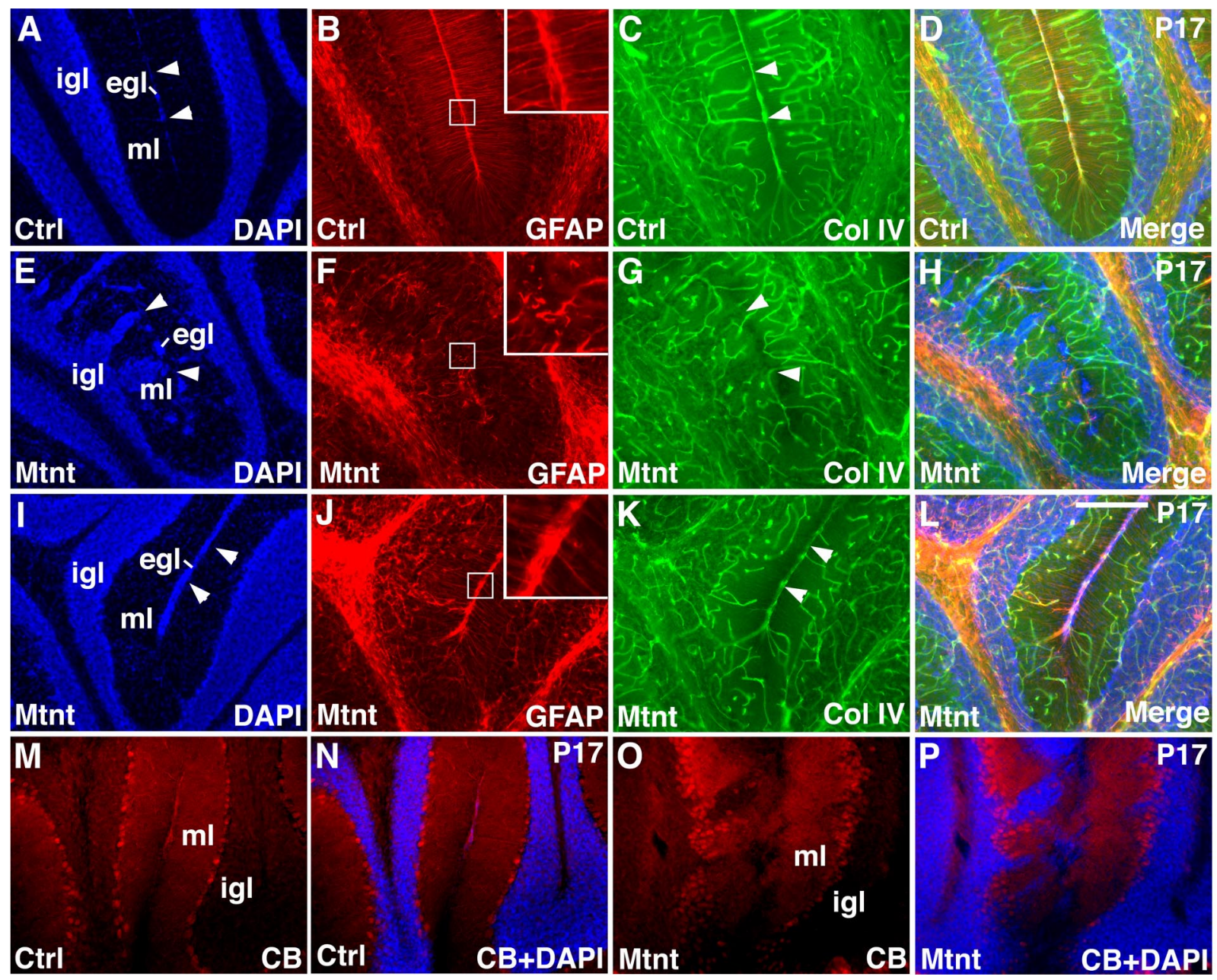

Figure 2. ric-8a deletion disrupts Bergmann glial scaffolding, granule cell migration and Purkinje cell positioning. $A-L$, Perturbed granule cell localization, Bergmann glial scaffolding, and basement membrane assembly in ric-8a/hGFAP-cre mutants. In controls at P17, a minimal number of granule cell precursors (arrowheads in $A, E, I$ ), as revealed by DAPI staining, is found in the EGL (A). In contrast, in mutants, a large number of ectopic granule cell precursors are observed in the external granule as well as the molecular layer (ml) along principal fissures (E). An increased number of granule cell precursors also remain behind in the EGL along nonprincipal fissures in the mutants ( $\boldsymbol{I}$ ). In controls, GFAP-positive Bergmann glial fibers form a parallel scaffold at all fissures ( $\boldsymbol{B}$ ). In mutants, the scaffold is severely disrupted along most principal fissures $(\boldsymbol{F})$ and reduced in density along nonprincipal fissures $(\boldsymbol{J})$. In controls, Bergmann glial endfeet are anchored at the basement membrane (arrowheads in $\boldsymbol{C}, \boldsymbol{G}$, and $\boldsymbol{K}$; collagen IV staining) along all fissures ( $\boldsymbol{C}$ ). In mutants, the basement membrane is completely missing along main principal fissures (G), but remains relatively normal along nonprincipal fissures $(\boldsymbol{K}) \cdot \boldsymbol{M}-\boldsymbol{P}$, Perturbed Purkinje cell localization in ric-8a/hGFAP-cre mutants at $\mathrm{P} 17$. Calbindin staining reveals that, in contrast to their orderly localization at the border between the molecular and the internal granule layer in controls $(M, N)$, Purkinje cell body positioning is severely disrupted in mutants $(\boldsymbol{O}, \boldsymbol{P})$. Scale bar: $\boldsymbol{L}($ for $\boldsymbol{A}-\boldsymbol{P}), 200 \mu \mathrm{m}$. egl, external granular layer; igl, internal granule layer.

gration, with a minimal number remaining in the external granule layer (EGL; Fig. 2A). In contrast, in ric-8a/hGFAP-cre mutants (Fig. 2E-L), Bergmann glial scaffolds surrounding the primary and secondary fissures were severely disorganized (Fig. $2 F, H$ ). No apparent parallel scaffold could be observed and there was no basement membrane separating the neighboring lobules (Fig. 2G). Further, large numbers of granule cells were trapped throughout the molecular layer as well as in the EGL (Fig. $2 E$ ). Interestingly, we found that the Bergmann glial scaffolds surrounding other, mostly nonprincipal, fissures were still associated with basement membrane (Fig. $2 J-L$ ). These scaffolds, however, were nonetheless severely reduced in fiber density. An increased number of granule cells was also found trapped in the EGL at these fissures (Fig. 2I). Overall, the severity of Bergmann glial scaffold disorganization across different lobules appeared to closely relate to defects in granule cell migration. While large numbers of ectopic granule cells were found trapped in both the molecular and EGLs in lobules surrounding the primary and secondary fissures (Fig. $2 E$ ), in other lobules, obvious granule cell accumulation was observed only in the EGL but not in the molecular layer (Fig. 2 I). This latter appears to be consistent with the lower density but relatively normal organization of Bergmann glial fibers along these fissures (Fig. $2 \mathrm{~J}$ ). Thus, these results indicate a key role of Bergmann glial scaffold disorganization in ectopic granule cell positioning in ric- $8 a$ mutants.

Last, we examined Purkinje cells using an antibody against Calbindin, a well known Purkinje cell marker. In the control cerebellum, as expected, we observed a single row of Purkinje cell bodies that neatly aligned at the border between the molecular and the internal granule layer (Fig. $2 M, N$ ). In contrast, in ric-8a/hGFAP-cre mutants, Purkinje cell body localization was severely disrupted, with the cell bodies scattered over a wide area, and frequently intermingled with ectopic granule cells. These defects were most obvious in lobules surrounding the primary and secondary fissures (Fig. 2O,P). These results indicate that loss of ric- $8 a$ function also severely disrupts Purkinje cell positioning in the cerebellum. 


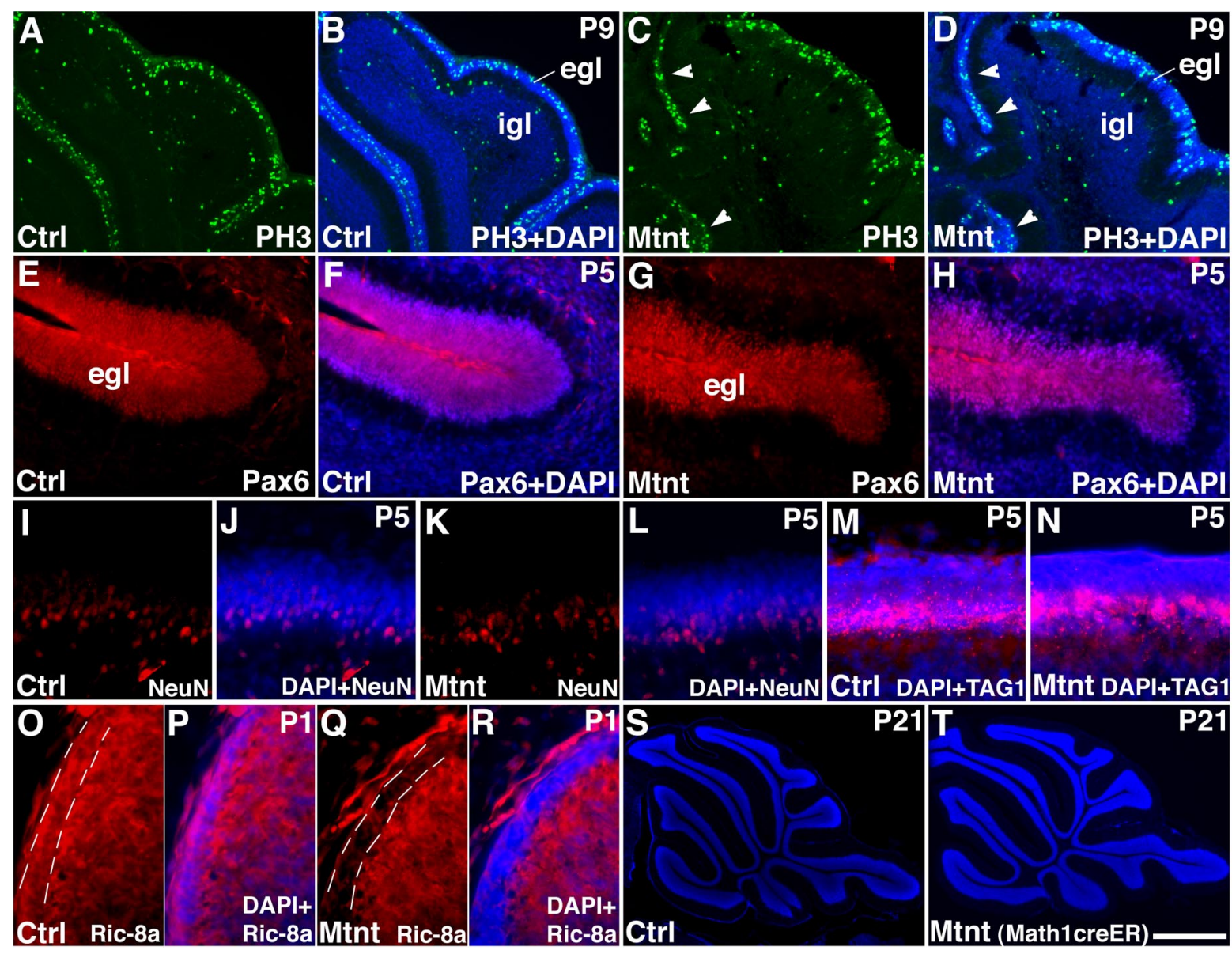

Figure 3. ric-8a is not required in granule cell precursors for normal cerebellar development. $\boldsymbol{A}-\boldsymbol{H}$, Normal proliferation and Pax6 expression by granule cell precursors in the EGL of ric-8a/hGFAPcre mutants. At $P 9$ in controls $(\boldsymbol{A}, \boldsymbol{B})$, granule cell precursors in the $E G L$ are undergoing rapid expansion and many are positive for PH3 $(\boldsymbol{A})$. A similar pattern is observed in mutants at this stage $(\boldsymbol{C}, \boldsymbol{D})$, even in regions with severe foliation defects (arrowheads in $($ and $\boldsymbol{D})$. At P5, granule cell precursors in the EGL also express similar levels of Pax 6 between controls $(\boldsymbol{E}, \boldsymbol{F})$ and mutants $(\boldsymbol{G}, \boldsymbol{H})$. $\boldsymbol{I}-\boldsymbol{N}$, Normal neuronal differentiation of granule cell precursors in the EGL of ric-8a/hGFAP-cre mutants. At P5 in controls, granule cell precursors in the inner sublayer of the EGL initiate postmitotic differentiation and stain positive for the neuronal marker NeuN $(\boldsymbol{I}, \boldsymbol{J})$. A similar pattern is observed in mutants $(\boldsymbol{K}, \boldsymbol{L})$. Quantification also shows no significant differences in the density of NeuN-positive cells between controls and mutants (see text). A similar pattern of TAG expression in the inner half of the EGL is also observed between controls and mutants at P5 (M, $\boldsymbol{N}$ ). $\mathbf{0}-\boldsymbol{R}$, Loss of Ric-8a protein from granule cell precursors in ric-8a/Math1-creERT2 mutants. At P1 in controls $(\boldsymbol{O}, \boldsymbol{P})$, strong Ric-8a immunoreactivity is observed in granule cell precursors in the EGL (between dash lines in $\mathbf{0}$ ). However, in mutants $(\boldsymbol{Q}, \boldsymbol{R})$, Ric-8a immunoreactivity is severely and selectively lost from the granule cell precursors (between dash lines in $\mathbf{Q})$. $\boldsymbol{S}, \boldsymbol{I}$, Deletion of $r i c-8 a$ from granule cell precursors using math 1 -creERT2 has no dramatic effects on cerebellar development. Similar overall foliation and granule cell migration are observed between controls $(\boldsymbol{S})$ and mutants $(\boldsymbol{T})$ at $P 21$. Scale bar: $\boldsymbol{T}$ (for $\boldsymbol{A}-\boldsymbol{D}), 100 \mu \mathrm{m}$; (for $\boldsymbol{E}-\boldsymbol{H}$ ), $100 \mu \mathrm{m}$; (for $\boldsymbol{I}-\boldsymbol{R}), 1 \mathrm{~mm}$; and (for $\boldsymbol{S}, \boldsymbol{T}), 1 \mathrm{~mm}$. igl, internal granule layer; egl, external granule layer.

ric- $8 a$ is not required in granule cell precursors for cerebellar development

A main driving force for cerebellar foliation is granule cell precursor proliferation in the EGL (Dahmane and Ruiz i Altaba, 1999; Wallace, 1999; Wechsler-Reya and Scott, 1999; Corrales et al., 2004; Lewis et al., 2004). To determine whether potential granule cell precursor defects play a role in the mutant phenotypes, we next examined granule cell precursor proliferation and differentiation at $\mathrm{P} 5-\mathrm{P}$, a stage when foliation is still in progress and large numbers of granule cells are also in the middle of migrating from the external to the internal granule layer. First, we used an antibody against phospho-histone 3 (PH3), a mitotic marker, to assess cell proliferation. In control cerebella, we observed a large number of $\mathrm{PH} 3$-positive granule cell precursors in the EGL (Fig. $3 A, B$ ). In mutants, we observed a similar number of $\mathrm{PH} 3$-positive cells (Fig. 3C,D), even in regions with severe foliation defects (although the number appears reduced in these regions at later stages). Quantification also showed that the density of PH3-positive cells along the EGL was not significantly different between controls and mutants (control, $70.8 \pm 6.3 / \mathrm{mm}$; mutant, $80.8 \pm 5.6 / \mathrm{mm} ; p=0.30, N=3)$. Similarly, the intensity of BrdU staining between controls and mutants was also comparable (data not shown). Thus, these results indicate that ric- $8 a$ mutation does not significantly affect granule cell precursor proliferation in the EGL. Next, we used an antibody against Pax6 to assess granule cell fate at P5. We found that Pax6 was expressed in the EGL at a comparable level between controls and mutants (Fig. $3 E-H)$. Similar results were also obtained using an anti-Math1 antibody (data not shown). Thus, granule cell fate determination is also not obviously affected by ric- $8 a$ loss of function. Last, to assess granule cell precursor differentiation, we used NeuN, a nuclear maker specific for neurons, to stain cells in the EGL. Granule cell precursors are known to begin postmitotic differentiation in the inner half of EGL. In controls, we observed specific NeuN staining in the innermost sublayer of the EGL (Fig. 3I,J). In mutants, we observed a similar pattern of NeuN staining (Fig. $3 K, L)$. Quantification showed that the density of NeuN-positive cells along the EGL was also not significantly different between controls and mutants (control, $24.8 \pm 1.5 / 100 \mu \mathrm{m}$ EGL; mutant, $25.0 \pm 1.5 / 100 \mu \mathrm{m} \mathrm{EGL} ; p=0.94, N=5)$. Further, we observed 
a similar pattern of TAG1 expression in the inner half of EGL between controls and mutants (Fig. $3 \mathrm{M}, N$ ). Thus, these results indicate that the timing of granule cell precursor differentiation is also normal in ric-8a/hGFAP-cre mutants. Therefore, altogether, these results indicate that granule cell precursor proliferation and differentiation are not obviously affected by ric- $8 a$ mutation.

To further assess potential ric- $8 a$ requirement in granule cells, we next used an inducible math1-creERT2 to delete ric-8a. Previous studies have shown that tamoxifen administration at E15.5 using this cre line induces widespread recombination specifically in granule cell precursors (Machold and Fishell, 2005). To increase the efficiency of ric- $8 a$ deletion, we also used animals heterozygous for a null and a conditional allele of ric- $8 a$, so that only one copy of ric-8a gene needs to be deleted in each granule cell precursor. We found that at P1, Ric-8a protein is strongly expressed in granule cell precursors in the control cerebellum (Fig. 3O,P). In contrast, following math1-creT2-induced recombination, Ric-8a protein is severely and specifically lost from these cells (Fig. $3 Q, R$ ). Thus, these results indicate that math1creT2 induces efficient and specific removal of Ric-8a protein from granule cell precursors at an early stage. Consistent with this finding, we observed recombination of ric-8a genomic DNA in close to $80 \%$ of cells in the mutant cerebellum (data not shown). However, despite the loss of Ric-8a protein from granule cell precursors at an early stage, we observed no significant defects, similar to those in ric-8a/hGFAP-cre mutants, in cerebellar development in ric-8a/math1-creERT2 animals, either at the gross anatomical level (Fig. 3S,T), or following staining for various markers (data not shown). Thus, these results indicate that ric-8a is largely dispensable from granule cell precursors for normal cerebellar development. Thus, these results indicate that ric-8a is primarily required in Bergmann glia, but not in granule cell precursors, for cerebellar morphogenesis.

\section{ric-8a is essential for Bergmann glia-basement membrane interaction and Bergmann glial scaffold organization}

Our results so far indicate a specific requirement for ric-8a in Bergmann glia for cerebellar foliation. To further analyze ric- $8 a$ function, we next examined effects of ric-8a mutation on cerebellar morphogenesis at earlier developmental stages. First, we used antibodies against the basement membrane component Laminin as well as DAPI staining to examine basement membrane morphology and gross anatomy at P0 and P4 (Fig. 4). We found that, in control cerebella, all four principal fissures, especially the preculminate and primary fissures, had significantly invaginated into the interior of cerebellum by the time of birth (Fig. 4A-C). All fissures were also supported by basement membrane along their entire length, from the mouth to the base. In contrast, in mutants, although the posterolateral fissure appeared relatively normal, the primary and secondary fissures completely failed to form (Fig. $4 D-F$ ). While granule cell ingression was observed at the presumptive sites, the basement membrane, instead of invaginating concomitantly with the granule cells, remained at the surface. As a result, granule cell precursors that had migrated internally not only failed to be separated, as under normal condition, into two prospective lobules, but were also completely devoid of contact with the basement membrane (Fig. 4E,F). Further, the development of preculminate fissure, although seemingly well supported by basement membrane at this stage, was also significantly delayed, with fissure ingression severely behind that in controls (Fig. $4 E, F$ ). Thus, these results indicate that ric-8a mutation disrupts cerebellar foliation from an early developmental stage. In all mutant cerebella, however, the basement membrane on the external cerebellar surface, although failing to invaginate at most fissure sites, remains continuous at this stage (Fig. $4 D, F$ ). This suggests that ric-8a function is not essential for basement membrane integrity maintenance per se, but is primarily required for the retention and subsequent assembly of basement membrane at emerging fissures.

To further analyze effects of ric-8a mutation on the basement membrane, we next examined P4 cerebella. In controls at P4, we found that all the principal fissures had invaginated deep into the cerebellum (Fig. 4G-I'). A number of nonprincipal fissures had also formed at this stage (Fig. 4G, asterisks). Most importantly, we found that at this stage all fissures were supported by basement membrane along their entire length, from the mouth to the base (Fig. 4I, $I^{\prime}$ ). In contrast, in mutants, most fissures still lacked basement membrane support at their base and along most of their length (Fig. $4 J-L^{\prime}$ ). In particular, at the primary fissure, although the granule cell precursors had migrated further interiorly, the basement membrane not only failed to catch up, but still remained at the cerebellar surface, where it had been at P0 (Fig. $4 J-L)$. Moreover, at newly formed nonprincipal fissures, basement membrane also failed to keep pace with granule cell ingression (Fig. 4, compare $G^{\prime}-I^{\prime}, J^{\prime}-L^{\prime}$ ). Thus, these results indicate that ric-8a mutation results in compromised retention and consequently timely assembly of basement membrane along both principal and nonprincipal fissures. However, similar to what we observed at $\mathrm{P} 0$ (Fig. $4 D, F$ ), at $\mathrm{P} 4$, the basement membrane on the cerebellar external surface remained intact (Fig. $4 J, L$ ). Since from P0 to P4 the volume of cerebellum has expanded significantly, this observation reinforces the interpretation that ric-8a does not primarily regulate basement membrane integrity per se, but is instead required for the retention and subsequent assembly of basement membrane at developing fissures.

Bergmann glial scaffold organization is known to be essential for proper cerebellar morphogenesis (Delaney et al., 1996; GrausPorta et al., 2001; Qu and Smith, 2005; Yue et al., 2005; Belvindrah et al., 2006; Mills et al., 2006; Qiu et al., 2010). To examine effects of ric-8a mutation on Bergmann glial differentiation and Bergmann glia-basement membrane interaction, we next stained cerebellar sections with antibodies against Nestin and BLBP for Bergmann glia, and antibodies against Laminin for basement membrane. We found that, in controls at P4, Nestin-positive Bergmann glial fibers formed a neatly aligned parallel scaffold anchored to Laminin-positive basement membrane in the fissures (Fig. $5 A-D$ ). In contrast, in mutants at P4, Bergmann glial fibers along most fissures were not anchored to the basement membrane (Fig. $5 E-L$ ). Sometimes they were found anchored to the basement membrane of a blood vessel that happened to run nearby (Fig. $5 E-H$ ). At other times, they completely lacked contact with any basement membrane (Fig. 5I-L). In all cases, Bergmann glial scaffold appeared notably disrupted and the fiber density was severely reduced. Similarly, in controls at P5, we observed a nicely organized BLBP-positive scaffold along all fissures (Fig. $5 M-P$ ). In addition, Bergmann glial cell bodies also formed in a tightly aligned layer at the base of the scaffold. In contrast, in mutants, no clear organization of glial fibers could be discerned (Fig. 5Q-T). Further, Bergmann glial cell bodies were also scattered in a wider area and failed to form a tight layer. Thus, these results indicate that, during early cerebellar development, ric-8a mutation results in compromised basement membrane retention and assembly, and consequently severely reduced Bergmann glia-basement membrane interaction, along developing fissures, which in turn leads to defective Bergmann glial scaffold 


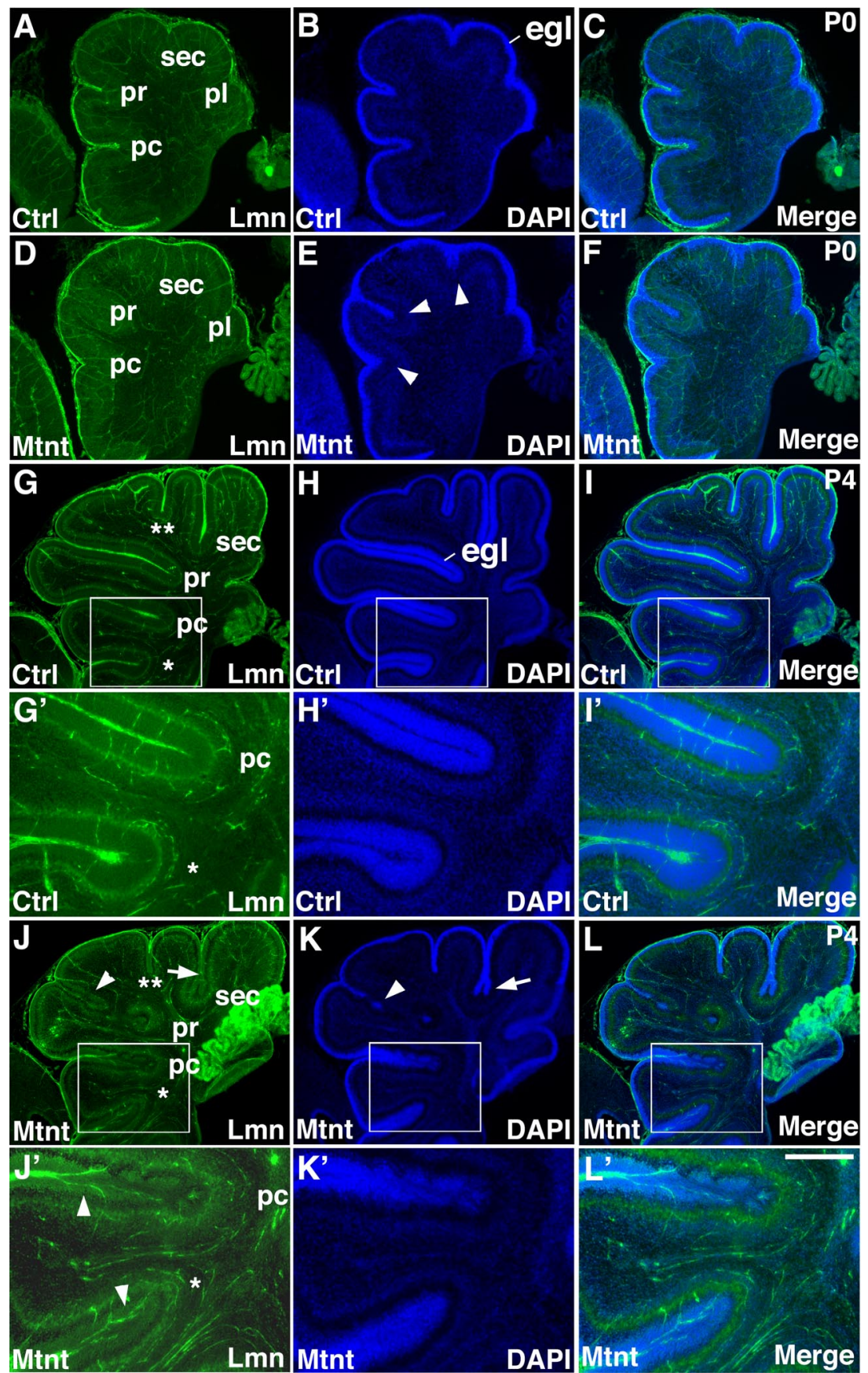

Figure 4. Cerebellar defects in ric-8a/hGFAP-cre mutants arise from failed basement membrane retention at developing fissures during early postnatal stages. $\boldsymbol{A}-\boldsymbol{F}$, Basement membrane morphology and fissure formation at $P 0$. In controls $(\boldsymbol{A}-\boldsymbol{C})$, Laminin staining reveals presence of basement membrane at the base as well as along the entire length of all principal fissures ( $\mathrm{pc}$, preculminate; $\mathrm{pr}$, primary; sec, secondary; $\mathrm{pl}$, posterolateral fissure). In contrast, in mutants $(\boldsymbol{D}-\boldsymbol{F})$, basement membrane is completely absent from the presumptive primary and secondary fissures, even though a large number of granule cells have migrated internally ( $\boldsymbol{E}$, arrowheads). Basement membrane on the cerebellar surface, however, remains continuous, both over these presumptive fissure sites and in other regions. $\mathbf{G}-\mathbf{L}^{\prime}$, Basement membrane morphology and fissure formation at P4. In controls $\left(\mathbf{G}-\mathbf{I}^{\prime}\right)$, most principal fissures have invaded deep into the cerebellum by $\mathrm{P} 4$, and are supported along their entire length by basement membrane. Several nonprincipal fissures have also developed and are similarly supported by basement membrane (asterisks in $G$ ). In contrast, in mutants $\left(J-L^{\prime}\right)$, the primary fissure still completely lacks basement membrane at P4 (arrowheads in $\boldsymbol{J}$ and $\boldsymbol{K}$ ). Other principal as well as nonprincipal fissures, although partially invested with basement membrane, still lack support at their base (arrows in J and $\mathbf{K}$; arrowheads in $J^{\prime}$ ). Nonetheless, similar to P0, basement membrane on the external cerebellar surface remains continuous. Boxed areas in $\mathbf{G}-\boldsymbol{L}$ are shown in detail in $\boldsymbol{G}^{\prime}-\boldsymbol{L}^{\prime}$. Scalebar: $\boldsymbol{L}^{\prime}($ for $\boldsymbol{A}-\boldsymbol{L}), 500 \mu \mathrm{m}$ and (for $\left.G^{\prime}-L^{\prime}\right), 200 \mu \mathrm{m}$. egl, External granule layer.

and cell body organization. As a consequence, these defects may underlie the disruption in granule cell precursor migration (from the external to the internal granule layer) that we observed at later stages (Fig. 2). Last, we also examined Bergmann glia-basement membrane interaction at $\mathrm{P} 0$, a stage when foliation just starts at the prospective secondary fissure (Fig. $5 U-B B$ ). We found that, at this stage, Bergmann glial scaffold displayed similar morphology between controls and mutants (Fig. 5, compare $U$, $Y)$. In particular, in cerebella of both genotypes, Bergmann glial fibers similarly reorganized into a characteristic fan shape beneath the presumptive fissure site, as has been previously reported in normal cerebellar development (Sudarov and Joyner, 2007). In contrast, although they maintained adhesion to the basement membrane in controls, in mutants, the endfeet of Bergmann glial fibers completely lost connection to the basement membrane (Fig. 5, compare $Z, B B ; V, X$ ). Thus, these results further indicate that ric-8a does not affect Bergmann glial fiber scaffold reorientation during the onset of fissure formation, but instead specifically regulates Bergmann glia-basement membrane adhesion at this stage.

\section{ric-8a regulates Bergmann glia-}

basement membrane interaction in the embryonic cerebellar primordium

To further evaluate our interpretation that ric- 8 a primarily regulates Bergmann glia-basement membrane interaction at emerging fissures, we examined the morphology of both during embryogenesis, using mutants in which the ric-8a gene had been deleted using a nestin-cre (Tronche et al., 1999; Graus-Porta et al., 2001). The ric-8a/nestin-cre mutants show similar cerebellar foliation defects to those of ric-8a/hGFAP-cre mutants at P0 (data not shown), but die shortly after birth. We found that, at E17.0, control and mutant cerebellar primordia showed similar patterns of staining for all markers examined (Fig. 6A-H). In the EGL, both controls and mutants showed slightly thickened nuclear DAPI staining at the sites of prospective primary and secondary fissures (Fig. 6C,G). Bergmann glial fibers also displayed similar initial signs of reorganization into a fan shape at these sites (Fig. $6 B, D, F, H$ ) (Sudarov and Joyner, 2007), while no obvious morphological indentation in the surface basement membrane was yet observable in either genotype (Fig. $6 A, E)$. These observations indicate that cerebellar foliation defects in ric-8a mutants first arise after E17.0. Indeed, at E17.5, while in controls, we observed significant ingression at all principal fissures, concomitant with obvious indentation of the surface basement membrane (Fig. 6I-L); in mutants, no significant invagination of the basement membrane was observed at most fissures, even though obvious EGL thickening or granule cell ingression had 


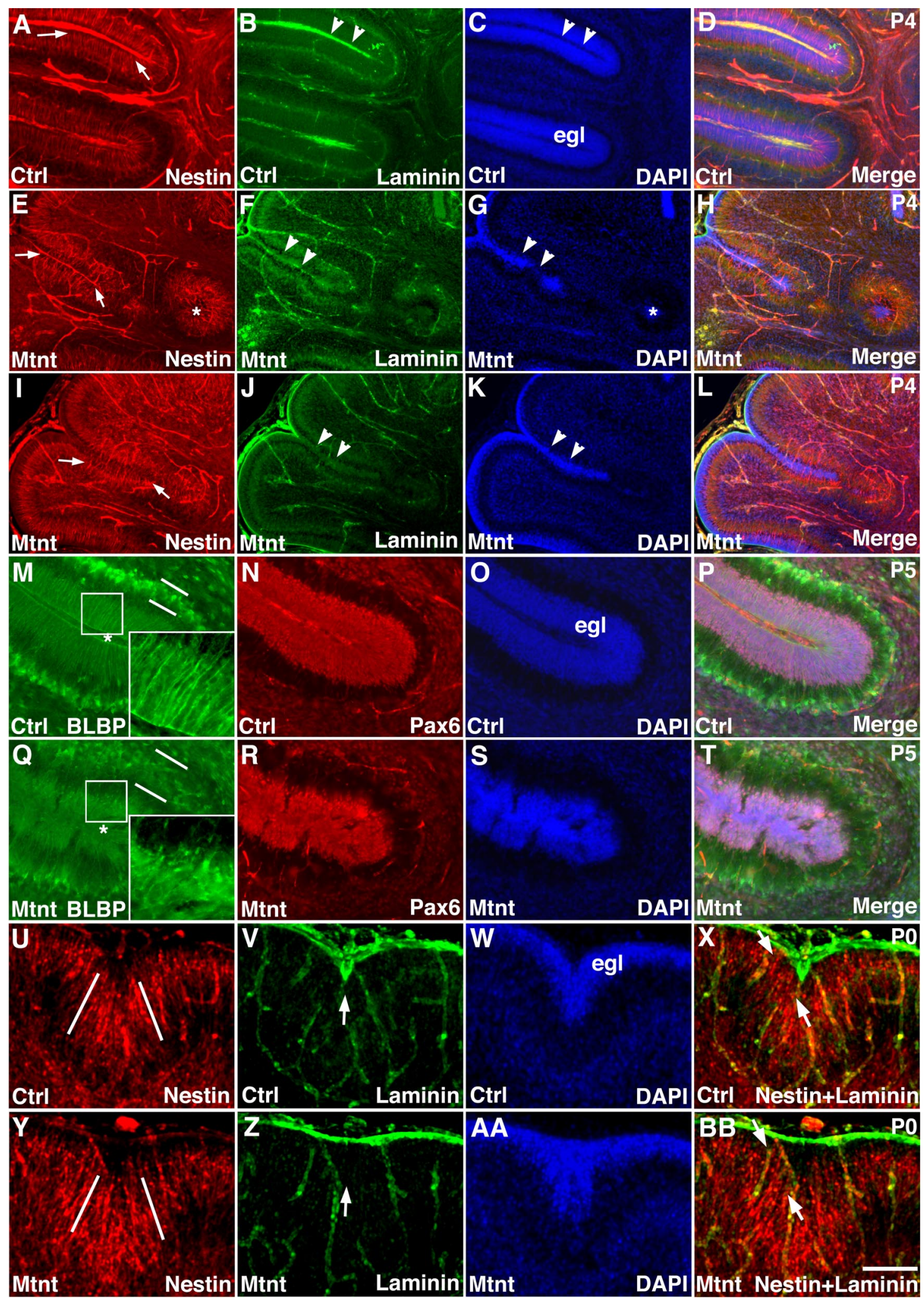

Figure 5. Defective Bergmann glial scaffold and Bergmann glia-basement membrane interaction in ric-8a/hGFAP-cre mutants during early postnatal development. $A-L$, Bergmann glial fiber organization and Bergmann glia-basement membrane interaction at P4. In controls ( $\boldsymbol{A}-\boldsymbol{D})$, Nestin-positive Bergmann glial fibers form a parallel scaffold $(\boldsymbol{A}$, arrows), and their endfeet are anchored at the basement membrane that separates granule cells from neighboring lobules (arrowheads in $\boldsymbol{B}$ and $\boldsymbol{C}$ ). In contrast, in mutants $(\boldsymbol{E}-\boldsymbol{L})$, Bergmann glial fibers appear disorganized at the vast majority of fissures (arrows in $\boldsymbol{E}$ and $\boldsymbol{I}$ ). Although at some fissures they form a primitive scaffold by anchoring endfeet to the basement membrane of blood vessels nearby $(\boldsymbol{F}$, arrowheads), at other locations (asterisk in $\boldsymbol{E}$ ) or other fissures $(\boldsymbol{I})$, the glial fibers completely lack anchoring. Granule cells from neighboring lobules also fuse into a single layer (arrowheads in $\boldsymbol{G}$ and $\boldsymbol{K}$ ). $\boldsymbol{M} \boldsymbol{-} \boldsymbol{T}$, Bergmann glial fiber scaffold and cell body organization at P5. In controls $(M-P)$, BLBP staining reveals a parallel scaffold of glial fibers spanning the EGL (inset in $M$ ). In addition, Bergmann glial cell bodies form a tight layer beneath the EGL (between white bars in $\boldsymbol{M}$ ). In contrast, in mutants $(\mathbf{Q}-\boldsymbol{T})$, not only is the glial fiber scaffold disorganized (inset in $\mathbf{Q}$ ), their cell bodies are also dispersed over a wider area (between white bars in Q). Pax6 expression in the EGL, however, appears similar between controls $(\boldsymbol{N})$ and mutants $(\boldsymbol{R}) . \boldsymbol{U}-\boldsymbol{B B}$, Bergmann glial fiber organization and (Figure legend continues.) 
taken place and Bergmann glial scaffolds had also undergone major reorganization at all principal fissures (Fig. $6 M-P$ ). In particular, at the primary fissure, despite extensive granule cell and Bergmann glial scaffold ingression, the basement membrane remained at the surface. As a result, the presumptive primary fissure lacked basement membrane support not only at the base but also along the entire length. Thus, these results indicate that ric-8a mutation first disrupts Bergmann glia-basement membrane interaction between E17.0 and E17.5, at the very onset of foliation. This therefore further reinforces our interpretation that ric-8a function is primarily required in Bergmann glia for retaining basement membrane at emerging fissures at the onset of their formation.

To further assess potential contribution of granule cell precursor defects to the mutant phenotypes we observed, we next examined their proliferation at E18.5 (Fig. 6Q-BB). We found that, at E18.5, control and mutant cerebella showed similar patterns of PH3 staining in the EGL (Fig. 6, compare $Q, U$ ). Quantification showed that the numbers of PH3-positive cells was not statistically different between controls and mutants (control, $138 \pm 8$; mutant, $121 \pm 10 ; p=0.25 ; N=4)$. Pax6 expression in the EGL also appeared comparable between controls and mutants (Fig. 6, compare $R, V)$. Further, BrdU labeling also revealed a similarly strong incorporation in the EGL between controls and mutants (Fig. 6, compare $Y, A A$ ). Thus, these results indicate that potential defects in granule cell precursor proliferation also do not play a major role in cerebellar malformation during embryogenesis. Thus, these results altogether indicate that throughout embryonic and postnatal development, ric-8a function is specifically required in the Bergmann glia for regulating Bergmann gliabasement membrane adhesion, and consequently for the retention and assembly of basement membrane, at emerging fissures.

\section{ric-8a-deficient cerebellar glia show decreased affinity for basement membrane components}

Our results have implicated a specific role of $r i c-8 a$ in regulating Bergmann glia-basement membrane adhesion. To directly assess effects of ric-8a mutation on this interaction, we next used in vitro cell adhesion assays (Fig. 7). To this end, we coated coverslips with either poly-D-lysine or the basement membrane component Laminin and assessed cerebellar glial adhesion to these substrates in vitro. First, we used acutely dissociated P6 cerebellar cells. We found that cerebellar glia from control and mutant animals showed similar affinity to poly-D-lysine substrates in overnight assays. No significant percentile differences in GFAP-positive cells were observed between these genotypes (Fig. 7E). In contrast, on Laminin substrates, we observed a severe reduction in the adhesion of mutant glia (Fig. $7 A, B$ ). While $\sim 48 \%$ of adherent cells on Laminin substrates were GFAP positive for controls, only $31 \%$ were GFAP positive for mutants (Fig. $7 E$ ). Thus, these results indicate that ric- $8 a$ mutation severely compromises the

\section{$\leftarrow$}

(Figure legend continued.) their interaction with the basement membrane at $\mathrm{P}$. In controls at $\mathrm{PO}(\boldsymbol{U}-\boldsymbol{X})$, Bergmann glial fibers reorganize into a fan shape beneath the developing secondary fissure (between white bars in $\boldsymbol{U}$ ), while in the meantime maintaining adhesion to the basement membrane (between arrows in $\boldsymbol{X}$ ). In contrast, in mutants $(\boldsymbol{Y}-\boldsymbol{B} \boldsymbol{B})$, although Bergmann glial fibers also reorganize into a fan shape (between white bars in $\eta$, they fail to maintain adhesion to the pial basement membrane, but instead appear to interact with blood vessels (between arrows in $\boldsymbol{B B}$ ). As a result, unlike in controls, pial basement membrane remains on the surface in mutants (arrows in $\boldsymbol{V}$ and $\boldsymbol{Z}$ ). Scale bar: $\boldsymbol{B} \boldsymbol{B}$ (for $\boldsymbol{A}-\boldsymbol{T}$ ), $200 \mu \mathrm{m}$ and (for $\boldsymbol{U}-\boldsymbol{B} \boldsymbol{B}$ ), 100 $\mu \mathrm{m}$. egl, external granule layer. affinity to the Laminin substrate by cerebellar glia, a cell type that includes all Bergmann glia.

To ensure that the decreased affinity in glial adhesion we observed was not due to increased adhesion by nonglial cell types, we next used cell preparations with an enriched glial population. We first cultured dissociated cerebellar cells for $2 \mathrm{~d}$, which, as reported, yielded a highly enriched glial preparation (Belvindrah et al., 2006). Indeed, we found that $>92 \%$ of the cells in these preparations stained positive for GFAP. Next, we assayed the adhesion of these cells to poly-D-lysine and Laminin substrates overnight. We found that, similar to acutely dissociated cells, GFAP-positive cells in the glia-enriched preparations showed similar affinity to poly-D-lysine between controls and mutants (Fig. $7 F$ ). Their ability to adhere to Laminin, however, was severely compromised by ric-8a mutation (Fig. $7 C, D$ ). While the cell density on Laminin substrates was on average 432 cells $/ \mathrm{cm}^{2}$ for controls, the density was $\sim 178$ cells $/ \mathrm{cm}^{2}$ for mutants, a change that represents a close to $60 \%$ drop in cell adhesion (Fig. $7 F$ ). Last, to rule out potential effects of ric- $8 a$ mutation on cell survival and/or differentiation, we also performed a $1 \mathrm{~h}$ adhesion assay using acutely dissociated cerebellar cells. We found that, while control and mutant glia showed no significant differences in their affinity for poly-D-lysine substrates, mutant glia, similar to those in overnight assays, also showed $>60 \%$ reduction in adhesion to the Laminin substrate (Fig. 7G). Thus, these results together reinforce the interpretation that ric-8a mutation compromises the affinity of cerebellar glia to basement membrane components, and provide further support for the conclusion that ric-8a regulates Bergmann glia-basement membrane interaction in vivo during cerebellar development.

\section{Deletion of $\beta 1$ integrin from Bergmann glia results in similar defects in cerebellar foliation}

Cell substrate adhesion is best known to be mediated by the integrin class of cell adhesion molecules, of which $\beta 1$ integrins are major members. Thus, if ric-8a regulates the enhanced Bergmann glia-basement membrane interaction during cerebellar foliation and its mutation results in cerebellar fissure malformation, one would predict that $\beta 1$ integrin loss of function in Bergman glia may also compromise their interaction with basement membrane, and lead to similar foliation defects. Indeed, severe cerebellar defects, including compromised foliation, have been reported in $\beta 1$ integrin conditional mutants, where $\beta 1$ integrin was deleted using the nestin-cre (Graus-Porta et al., 2001). However, since $\beta 1$ integrin has been found to be essential for several different processes of cerebellar development, including Sonic hedgehog-driven granule cell precursor proliferation (Blaess et al., 2004), the relative contribution to these phenotypes of $\beta 1$ integrin function in granule cell precursors versus Bergmann glia was unclear. To overcome this complication, we used an inducible nestin-creER line to specifically delete $\beta 1$ integrin from the Bergmann glia (Burns et al., 2007).

To assess the specificity, we first examined patterns of recombination induced by nestin-creER (Burns et al., 2007), using the $m$ Tomato/mEGFP dual fluorescent reporter (Muzumdar et al., 2007), the same line we used to assess the recombination by $h G F A P$-cre (Fig. $1 A-H$ ). We found that administration of tamoxifen around E18.0, but not at earlier stages, using nestincreER, resulted in a relatively specific recombination in Bergmann glia in a mosaic pattern (Fig. $8 A-C$ ). At P7, $\sim 1$ week after Cre activation, we observed frequent clusters of mEGFPexpressing cells in the prospective molecular layer (Fig. 8A). Most of these mEGFP-positive cells displayed elongated fibers 


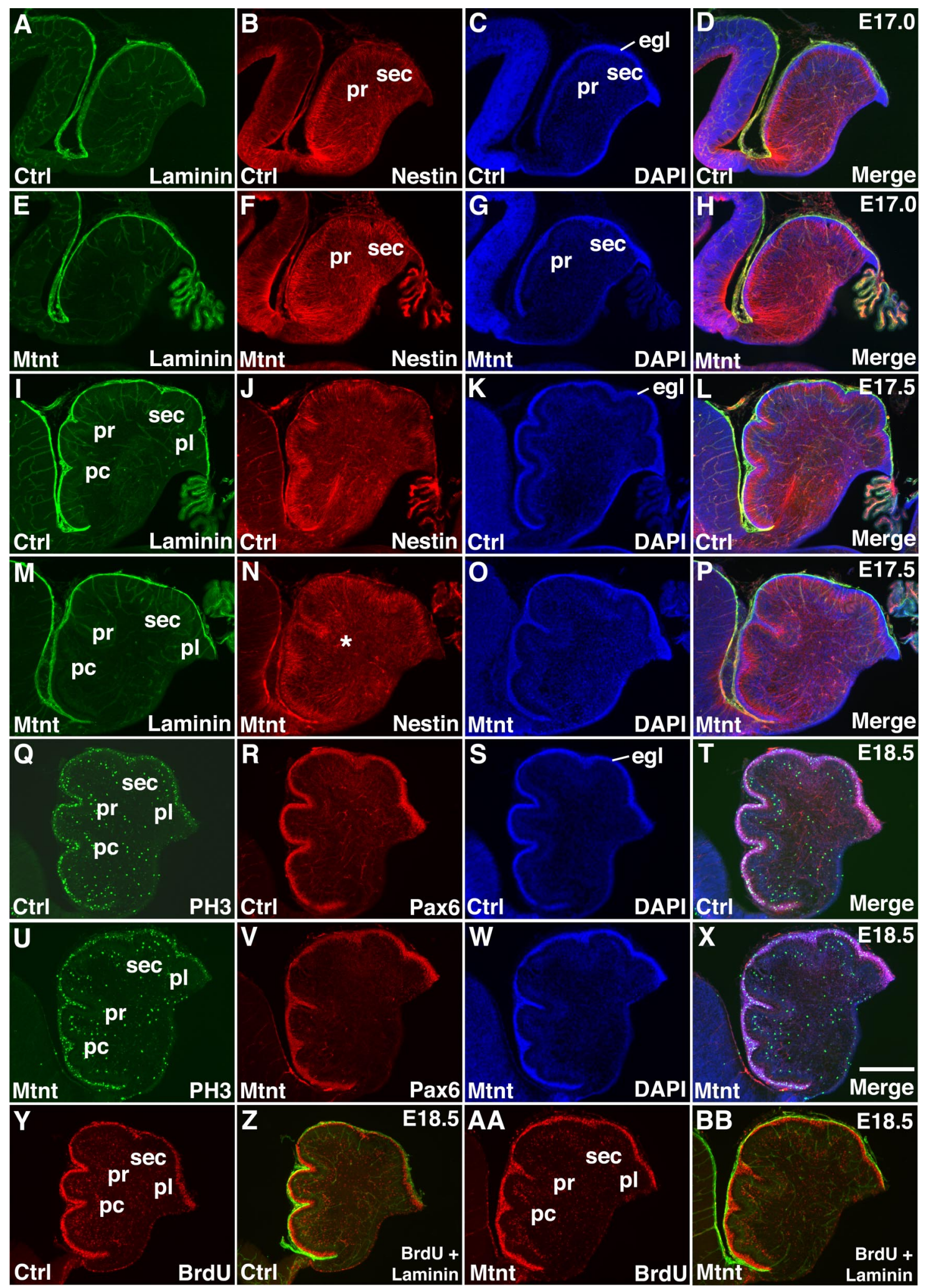

Figure 6. Defective basement membrane retention at the developing fissures in the embryonic cerebellum of ric-8a/nestin-cre mutants. $\boldsymbol{A}-\boldsymbol{H}$, Bergmann glial fiber organization and basement membrane morphology at E17.0. Subtle signs of Bergmann glial fiber reorganization and EGL thickening can be similarly observed at prospective primary and secondary fissure sites in both controls $(\boldsymbol{B}, \boldsymbol{C})$ and mutants $(\boldsymbol{F}, \boldsymbol{G})$ at E17.0, while no obvious indentations are noticed in the basement membrane in either controls $(\boldsymbol{A})$ or mutants $(\boldsymbol{E})$. $\boldsymbol{I}-\boldsymbol{P}, \mathbf{B e r g m a n n}$ glial fiber organization and basement membrane morphology at E17.5. In controls at E17.5 (I-L), clear basement membrane invagination begins to appear at most prospective primary fissures $(\boldsymbol{I})$, concomitant with Bergmann glial fiber reorganization beneath $(\boldsymbol{J})$. In contrast, in mutants $(\boldsymbol{M}-\boldsymbol{P})$, despite similar progress in Bergmann glial fiber reorganization (asterisk in $\boldsymbol{N})$, basement membrane invagination fails to take place $(\boldsymbol{M})$. $\mathbf{Q}-\boldsymbol{B} \boldsymbol{B}$, Granule cell precursor proliferation and Pax6 expression at E18.5. Similar levels of PH3 staining as well as Pax6 expression are observed in the EGL between controls ( $\mathbf{Q}, \boldsymbol{R})$ and mutants $(\boldsymbol{U}$, V. Similarly strong BrdU incorporation is also observed in the $\mathrm{EGL}$ between controls $(\boldsymbol{Y}, \boldsymbol{Z})$ and mutants $(\boldsymbol{A} \boldsymbol{A}, \boldsymbol{B} \boldsymbol{B})$. Scale bar: $\boldsymbol{X}(\mathrm{for} \boldsymbol{A}-\boldsymbol{B} \boldsymbol{B})$, $500 \mu \mathrm{m}$. egl, external granule layer; $\mathrm{pc}$, preculminate; pr, primary; sec, secondary; pl, posterolateral fissure. 


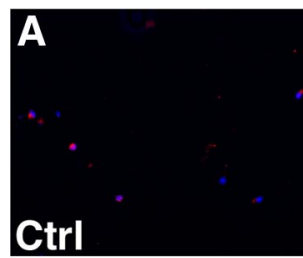

E

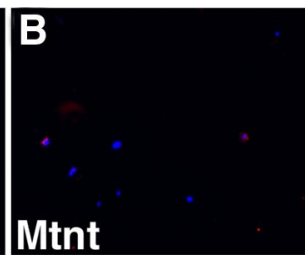

$F_{0}$

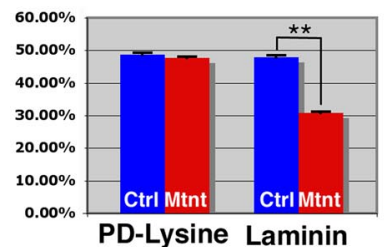

1000

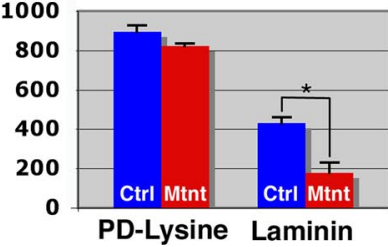

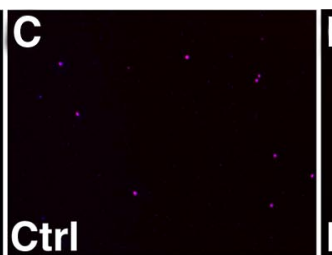

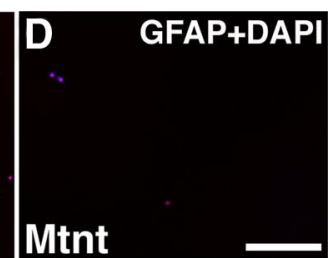

G Density of GFAP+ Cells

$\left(\mathrm{cm}^{-2}, 1\right.$ hour assay)

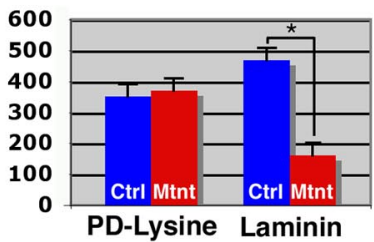

Figure 7. ric-8a mutation results in reduced cerebellar glial affinity for Laminin. $\boldsymbol{A}-\boldsymbol{B}, 0$ vernight adhesion assay of acutely dissociated cerebellar cells on Laminin substrates. A higher percentage of cells (DAPI staining in blue) are GFAP-positive (in red) in controls (Ctrl, $\boldsymbol{A}$ ) than in mutants (Mtnt, $\boldsymbol{B}$ ) on Laminin substrates. No significant difference is observed on poly-D-lysine (PD-Lysine) substrates (quantification in $\boldsymbol{E}$ ). $(-\boldsymbol{D}, 0$ vernight adhesion assay of glia-enriched cerebellar cells on Laminin substrates. A higher number of cells adhere to the Laminin substrate in controls ( $\boldsymbol{C}$ ) than in mutants $(\boldsymbol{D})$. No significant difference is observed on poly-D-lysine substrates (quantification in $\boldsymbol{F}$ ). $\boldsymbol{E}$, Quantification of GFAP-positive cells on poly-D-lysine and Laminin substrates in overnight adhesion assay of acutely dissociated cerebellar cells. ${ }^{* *} p=0.003, N=3$ animals for each condition. $\boldsymbol{F}$, Quantification of GFAP-positive cells on poly-D-lysine and Laminin substrates in overnight adhesion assay of glia-enriched cerebellar cells. ${ }^{*} p=0.02, N=3$ animals for each condition. G, Quantification of GFAP-positive cells on poly-D-lysine and Laminin substrates in $1 \mathrm{~h}$ adhesion assay of acutely dissociated cerebellar cells. ${ }^{*} p=0.02, N=3$ animals for each condition. Scale bar: $\boldsymbol{D}$ (for $\left.\boldsymbol{A}, \boldsymbol{B}\right), 100 \mu \mathrm{m}$ and (for $\left.\boldsymbol{C}, \boldsymbol{D}\right), 200 \mu \mathrm{m}$.

that spanned the EGL, indicating that they belonged to Bergmann glia. On the other hand, the vast majority of cerebellar cells, including most in the Bergman glial and Purkinje cell layers as well as those in the external and internal granule layers, continued to express mTomato (Fig. $8 \mathrm{~B}$ ). Thus, these results indicate that administration of tamoxifen at E18.0 using the nestin-creER line results in a relatively specific Cre activation in Bergmann glia.

To determine effects of $\beta 1$ integrin deletion from subsets of Bergmann glia, we next introduced the nestin-creER transgene into the $\beta 1$ integrin conditional mutant background, and administered tamoxifen at E18.0. We found that this resulted in frequent areas of reduced $\beta 1$ integrin immunoreactivity at the endfeet of Bergmann glia (Fig. $8 D-G$ ), in a pattern similar to that of mEGFP expression observed using the mTomato/mEGFP reporter (Fig. $8 A$ ). This indicates loss of $\beta 1$ integrin protein from subsets of Bergmann glia. Indeed, consistent with $\beta 1$ integrin loss of function, we observed significant cerebellar defects in these animals, similar to those in ric- $8 a / h G F A P$-cre mutants. In controls at P19, we observed, as expected, a neatly organized Bergmann glial scaffold along all early forming fissures (Fig. $8 \mathrm{H}$ ). The internal migration of granule cells from the external to the internal granule layer had also largely been completed, with a minimal number of granule cells remaining in the EGL (Fig. 8I). In contrast, in $\beta 1$ integrin mutants, along many fissures, we frequently observed disorganized Bergmann glial scaffolds, where the glial fibers appeared loose and wavy (Fig. $8 \mathrm{~K}$ ). An increased number of granule cell precursors was also observed in the EGL (Fig. $8 \mathrm{~L}$ ), suggesting delay in their internal migration. Indeed, quantification confirmed a significant increase in the number of granule cell precursors that remained in the EGL (control, $111 \pm 14 / \mathrm{mm}$ EGL; mutant, $278 \pm 41 / \mathrm{mm}$ EGL; $p=0.02, N=4)$. In contrast to mutants in which $\beta 1$ integrin was deleted using nestin-cre (GrausPorta et al., 2001), however, the fissural basement membrane appeared normal in these nestin-creER mutants (data not shown). This is likely due to the relatively late timing by which $\beta 1$ integrin was deleted. Thus, these results indicate that, similar to ric- 8 a mutation, weakening Bergmann glia-basement interaction by $\beta 1$ integrin deletion from subsets of Bergmann glia also results in disrupted glial scaffold organization along cerebellar fissures, and consequently compromised migration of granule cell precursors from the external to the internal granule layer.

To further assess effects of $\beta 1$ integrin deletion, we next examined cerebellar foliation at late-forming fissures. At P19 in controls, most late-forming fissures had completed their ingression. Along these fissures, we also observed a nicely organized Bergmann glial scaffold spanning the molecular layer and a minimal number of residual granule cells in the EGL (Fig. $8 N-P$ ). In contrast, in mutants, we found that the ingression of several fissures that normally develop last was severely compromised (Fig. 8Q$S$ ). At their prospective sites, we observed only the initial signs of fissure formation, in which the Bergmann glial fibers underwent their characteristic reorganization into a fan shape (Fig. 8Q). Fissure ingression, however, failed to take place. The endfeet of Bergmann glial fibers at these sites also failed to maintain adhesion to the basement. As a result, the remaining granule cell precursors lost access to the Bergmann glial scaffold and appeared trapped in the EGL at the presumptive fissure site (Fig. $8 R, S$ ). Thus, these results indicate that similar to ric- $8 a, \beta 1$ integrin function in the Bergmann glia is also essential for fissure formation during cerebellar foliation. When $\beta 1$ integrin is removed from subsets of Bergmann glia, their interaction with basement membrane is weakened, which leads to failed fissure ingression. These similarities between $\beta 1$ integrin and ric- $8 a$ mutant phenotypes thus further support our interpretation that ric- $8 a$ specifically regulates Bergmann glia-basement membrane adhesion at the onset of fissure formation during cerebellar foliation.

\section{Discussion}

Previous studies have implicated a large number of cell adhesion molecules and associated proteins in maintaining basement membrane integrity during cerebellar development (GrausPorta et al., 2001; Qu and Smith, 2005; Belvindrah et al., 2006; Mills et al., 2006; Satz et al., 2008, 2010; Koirala et al., 2009). In all cases, these mutations affect the integrity of basement membrane both on the cerebellar external surface and along newly developed fissures, suggesting a general role of these genes in regulating cellbasement membrane interaction and basement membrane assembly/maintenance. Cell-basement membrane interaction, 

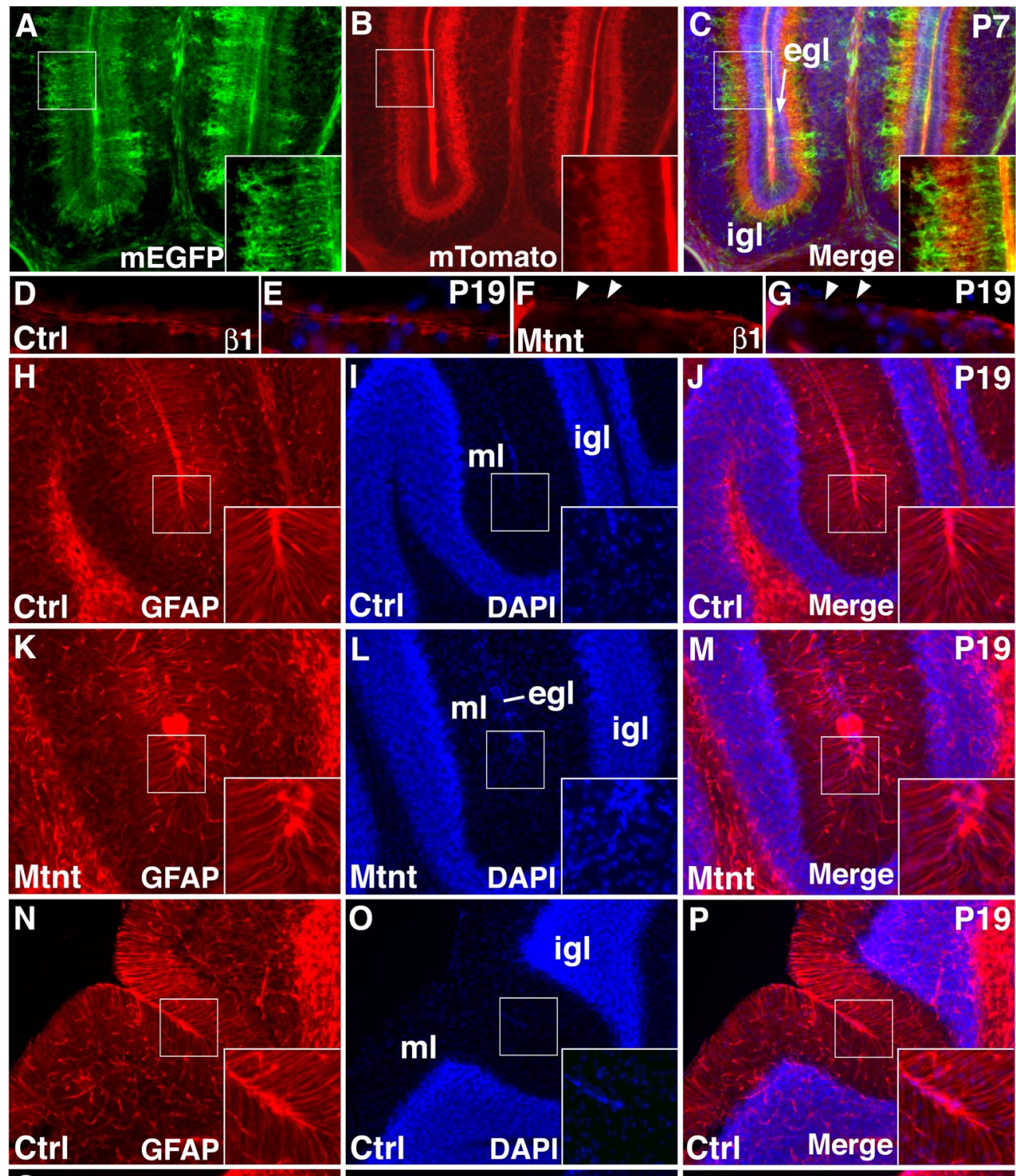

Merge
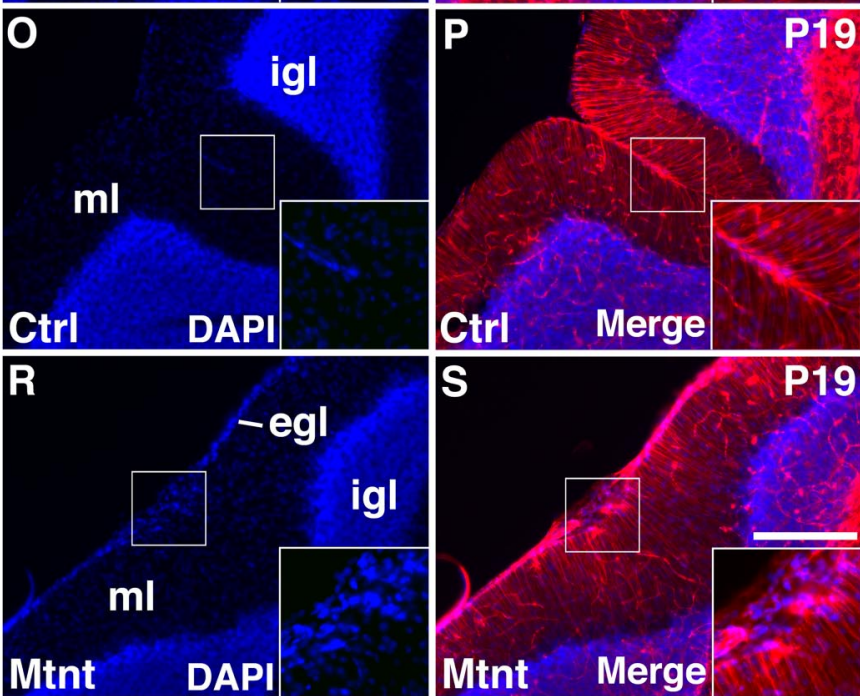

Figure 8. $\beta 1$ integrin deletion from Bergmann glia results in similar defects in cerebellar foliation. $A-C$, Patterns of cerebellar recombination induced by nestin-creER, as determined using the $m$ Tomato/ $m E G F P$ reporter. Tamoxifen administration at E18.0 results in reporter recombination and $m E G F P$ expression in clusters of Bergmann glia $(A)$, while remaining Bergmann glia and granule cell precursors appear unrecombined and continue to express mTomato $(\boldsymbol{B})$. $\boldsymbol{D}$ - $\boldsymbol{G}$, Reduction of $\beta 1$ integrin protein expression in mutant cerebella. In controls at $P 19, \beta 1$ integrin is strongly expressed in the Bergmann glial endfeet $(\boldsymbol{D}, \boldsymbol{E})$. In contrast, frequent gaps are observed in $\beta 1$ integrin/nestin-creER mutants (arrowheads in $\boldsymbol{F}$ and $\boldsymbol{G}) \cdot \boldsymbol{H}-\boldsymbol{M}, \boldsymbol{\beta} 1$ integrin deletion by nestin-creER perturbs Bergmann glial scaffold organization and granule cell migration. In controls at P19 $(\boldsymbol{H}-\boldsymbol{J})$, Bergmann glial fibers maintain a parallel scaffold along all fissures $(\boldsymbol{H})$, and a minimal number of granule cell precursors remain in the EGL $(\boldsymbol{I})$. In contrast, in mutants $(\boldsymbol{K}-\boldsymbol{M})$, Bergmann glial fibers along many fissures appear wavy, frequently crisscrossing each other $(\boldsymbol{K})$, and an increased number of granule cells remain in the EGL $(\boldsymbol{L}) . \boldsymbol{N}-\boldsymbol{S}, \beta 1$ integrin deletion by nestin-creER results in failed invagination of late-developing fissures. In controls at P19 (N-P), most late-forming fissures have finished formation $(\boldsymbol{N})$, and a minimal number of granule cell precursors remain in the EGL $(\mathbf{0})$. In contrast, in mutants $(\mathbf{Q}-\boldsymbol{S})$, although Bergmann glial fibers initiate reorganization into a fan shape at late-forming fissures $(\mathbf{Q})$, their endfeet frequently detach from the basement membrane and, as a result, fissures fail to invaginate $(\boldsymbol{R})$. Many granule cell precursors in the EGL at the presumptive fissure site also appear to lose access to the Bergmann glial scaffold and appear trapped ( $\boldsymbol{R}, \boldsymbol{S}$ ). Scale bar: $\boldsymbol{S}$ (for $\boldsymbol{A}-\boldsymbol{C}$ and $\boldsymbol{H}-\mathbf{S}), 200 \mu \mathrm{m}$ and (for $\mathbf{D}-\mathbf{G}), 50 \mu \mathrm{m}$. egl, external granule layer; igl, internal granule layer; $\mathrm{ml}$, molecular layer.

however, is highly dynamic during cerebellar development, especially during the process of foliation, when granule cell precursors and Bergmann glia, along with the supporting basement membrane, undergo ingression at select sites along the cerebellar sur- face, while remaining in place at other locations. This suggests differential regulation of cell-basement membrane interaction during the initiation of foliation. However, little is known, to date, about how this process is regulated at the molecular level. In 
this article, we demonstrate that Ric- $8 \mathrm{a}$, a guanine nucleotide exchange factor for several heterotrimeric $G$ proteins, plays an essential role in the Bergmann glia for regulating Bergmann gliabasement membrane interaction, specifically at the onset of cerebellar foliation. We show that ric-8a deletion from the cerebellum results in severe defects in lobule formation, granule cell migration, Purkinje cell localization, and Bergmann glial scaffold organization. We also show that ric-8a mutation does not significantly affect granule cell precursor proliferation or differentiation, and that cell type-specific deletion of ric-8a from the granule cell precursors does not result in similar phenotypes. These findings thus implicate a specific requirement for ric- $8 a$ in the Bergmann glia during cerebellar development. Moreover, we show that ric-8a mutation results in compromised basement membrane formation at developing fissures during both embryonic and early postnatal development, but has no primary effects on the integrity of basement membrane that remains on the cerebellar surface. We further show that these defects lead to, along the developing fissures, not only Bergmann glial fiber disorganization, but also cell body misalignment. These findings thus indicate that ric-8a plays a specific role in regulating Bergmann glia-basement membrane adhesion during the onset of fissure formation, but is largely dispensable for general basement membrane maintenance. This interpretation is further supported by our findings that glial cells isolated from ric-8a-deficient cerebella show reduced affinity for basement membrane components in vitro. Last, we show that weakening Bergmann glia-basement membrane interaction during cerebellar development, by removing $\beta 1$ integrin from subsets of Bergmann glia, also results in similar defects in cerebellar foliation. Thus, altogether, our results reveal novel insights into the molecular mechanisms that coordinate cerebellar foliation during brain development.

\section{Ric-8a function in Bergmann glia}

Ric-8a is widely expressed in the developing cerebellum. Using genetic approaches, we demonstrate that ric- $8 a$ is specifically required in the Bergmann glia during cerebellar foliation. We find that ric-8a deletion using math1-creERT2, which targets granule cell precursors (Machold and Fishell, 2005), has no dramatic effects on cerebellar development similar to hGFAP-cre. This indicates that ric- $8 a$ is not required in granule cell precursors for the process of foliation, although we cannot rule out ric- $8 a$ requirement for other developmental processes, or in adult function. In contrast, ric-8a deletion using hGFAP-cre or nestin-cre, mouse lines targeting most cerebellar neural cell types (Graus-Porta et al., 2001; Zhuo et al., 2001), results in severe defects in foliation. To our knowledge, this is the first time that a signaling molecule has been specifically implicated in the Bergmann glia for cerebellar foliation. It therefore provides a new venue for gaining insights into the intercellular signaling mechanisms that coordinate cerebellar morphogenesis.

At the biochemical level, Ric-8a has been found to enhance the exchange rate for GTP by several heterotrimeric G proteins as well as to serve as a molecular chaperone for their membrane association (Tall et al., 2003; Tall and Gilman, 2005; Thomas et al., 2008, 2011; Gabay et al., 2011; Thomas et al., 2011). This suggests that Ric-8a likely regulates heterotrimeric G-proteindependent signaling in the Bergmann glia and that this pathway is essential for maintaining strong Bergmann glia-basement membrane interaction during cerebellar foliation. As such, it appears probable that GPCRs may act upstream of Ric-8a in Bergmann glia. Along this line, it is interesting to note that Sonic hedgehoginduced granule cell precursor proliferation depends on G $\alpha \mathrm{i}$ function in vitro (Barzi et al., 2011). We did not observe obvious defects in granule cell precursor proliferation in ric-8a mutants. This suggests that ric- $8 a$ is not essential for Sonic hedgehog signaling in granule cell precursors. During cerebellar development, Purkinje cells are known to secrete Sonic hedgehog for inducing granule cell precursor proliferation, which in turn drives foliation, a process also coordinated with the Bergmann glia. In this vein, it would appear most parsimonious if Purkinje cell-derived Sonic hedgehog also signals to Bergmann glia to coordinate cerebellar morphogenesis. This speculation is particularly tempting in light of recent findings that Sonic hedgehog can activate cytoskeletal regulators through $\mathrm{G} \alpha \mathrm{i}$ proteins, in a manner independent of Gli-mediated transcriptional regulation (Polizio et al., 2011). However, other studies have shown that, although Sonic hedgehog can regulate Bergmann glial maturation in vitro, evidence for its involvement in Bergmann glial development in vivo is still lacking (Dahmane and Ruiz i Altaba, 1999; Lewis et al., 2004). Thus, further studies are needed to determine whether ric-8a may act in Sonic hedgehog signal transduction. Ric-8a has also been found to regulate GPCR-independent $\mathrm{G} \alpha$ function in invertebrates, especially in the process of asymmetric cell division (Afshar et al., 2004; David et al., 2005; Hampoelz et al., 2005; Wang et al., 2005). Thus, it is also possible that ric-8a may regulate GPCR-independent $\mathrm{G} \alpha$ function. Last, a recent study shows that Ric-8a regulates signaling by the receptor tyrosine kinase PDGFR (Wang et al., 2011). Thus, receptor tyrosine kinases are also potential candidates that may act upstream of Ric-8a.

\section{Bergmann glia-basement membrane interaction during cerebellar foliation}

Basement membrane integrity is critical for nervous system development, especially in the cerebral cortex and cerebellum. Several classes of cell adhesion molecules and related regulators, including dystroglycan, integrin, integrin-linked kinase, and Abl family tyrosine kinase, have been implicated in basement membrane assembly and maintenance in this process (Graus-Porta et al., 2001; Belvindrah et al., 2006; Mills et al., 2006; Satz et al., 2008, 2010; Qiu et al., 2010). Mutations in these genes result in both basement membrane breach and neuronal ectopia in the cerebellum. These defects are, however, in general more severe than those observed in ric-8a/hGFAP-cre mutants. In particular, in all these mutants, not only is the basement membrane along the developing fissures, but also that on the external cerebellar surface is compromised and marked by discontinuities. Since basement membrane is essential for granule cell precursor proliferation (Blaess et al., 2004), this results in, besides disruptions in the Bergmann glial scaffold, reductions in granule cell numbers and consequently smaller sizes of cerebellum. In contrast, in ric-8a mutants, basement membrane along the developing fissures is frequently missing, but when present, it remains continuous. Basement membrane on the external cerebellar surface is also consistently intact during early postnatal development. This indicates that there are no primary defects in basement membrane maintenance by ric-8a-deficient Bergmann glia. To our knowledge, this is also the first time that a signaling molecule has been identified that specifically regulates the strength of Bergmann glia-basement membrane interaction, while being largely dispensable for basement membrane integrity maintenance. This also reveals new insights into the mechanics of cerebellar foliation where the strength of Bergmann glia-basement membrane interaction appears to be differentially modulated at the cerebellar periphery, so that fissure formation can proceed smoothly at select sites. 


\section{Cerebellar foliation defects and human diseases}

It is increasingly recognized that, in addition to motor coordination, cerebellum is also critical for a significant number of higher order functions such as cognition, emotion, and language. The unique anatomy of the cerebellum, including the folia, is a key structural foundation for these functions. Indeed, it has been proposed that each individual folium may be an integrative module for unique sets of sensorimotor transactions (Welker, 1990). This hypothesis is supported by studies that localize particular sensorimotor tasks specifically to certain folia (Sillitoe and Joyner, 2007). Moreover, recent studies have also shown close correlation between the degree of cerebellar foliation and the complexity of behaviors displayed in different species of sharks (Yopak et al., 2007), which further suggests a role of foliation in cerebellar functional organization. Consistent with these observations, specific abnormalities in cerebellar fissuration and foliation in the vermis and/or the hemisphere have also been associated with developmental delay in human patients (Demaerel, 2002). However, despite significant insights into common cerebellar birth defects (Millen and Gleeson, 2008), the molecular mechanisms underlying these lesser known conditions remain poorly understood. Our implication of a role by ric- $8 a$ in specifically regulating Bergmann glia-basement membrane interaction during cerebellar foliation may therefore open a new venue for improved molecular understanding of these diseases.

\section{References}

Afshar K, Willard FS, Colombo K, Johnston CA, McCudden CR, Siderovski DP, Gönczy P (2004) RIC-8 is required for GPR-1/2-dependent Galpha function during asymmetric division of C. elegans embryos. Cell 119: 219-230.

Barzi M, Kostrz D, Menendez A, Pons S (2011) Sonic Hedgehog-induced proliferation requires specific Galpha inhibitory proteins. J Biol Chem 286:8067-8074.

Belvindrah R, Nalbant P, Ding S, Wu C, Bokoch GM, Müller U (2006) Integrin-linked kinase regulates Bergmann glial differentiation during cerebellar development. Mol Cell Neurosci 33:109-125.

Blaess S, Graus-Porta D, Belvindrah R, Radakovits R, Pons S, LittlewoodEvans A, Senften M, Guo H, Li Y, Miner JH, Reichardt LF, Müller U (2004) Betal-integrins are critical for cerebellar granule cell precursor proliferation. J Neurosci 24:3402-3412.

Borrell V, Marín O (2006) Meninges control tangential migration of hemderived Cajal-Retzius cells via CXCL12/CXCR4 signaling. Nat Neurosci 9:1284-1293.

Burns KA, Ayoub AE, Breunig JJ, Adhami F, Weng WL, Colbert MC, Rakic P, Kuan CY (2007) Nestin-CreER mice reveal DNA synthesis by nonapoptotic neurons following cerebral ischemia hypoxia. Cereb Cortex 17: $2585-2592$.

Corrales JD, Rocco GL, Blaess S, Guo Q, Joyner AL (2004) Spatial pattern of sonic hedgehog signaling through Gli genes during cerebellum development. Development 131:5581-5590.

Corrales JD, Blaess S, Mahoney EM, Joyner AL (2006) The level of sonic hedgehog signaling regulates the complexity of cerebellar foliation. Development 133:1811-1821.

Dahmane N, Ruiz i Altaba A (1999) Sonic hedgehog regulates the growth and patterning of the cerebellum. Development 126:3089-3100.

David NB, Martin CA, Segalen M, Rosenfeld F, Schweisguth F, Bellaïche Y (2005) Drosophila Ric-8 regulates Galphai cortical localization to promote Galphai-dependent planar orientation of the mitotic spindle during asymmetric cell division. Nat Cell Biol 7:1083-1090.

Delaney CL, Brenner M, Messing A (1996) Conditional ablation of cerebellar astrocytes in postnatal transgenic mice. J Neurosci 16:6908-6918.

Demaerel P (2002) Abnormalities of cerebellar foliation and fissuration: classification, neurogenetics and clinicoradiological correlations. Neuroradiology 44:639-646.

Gabay M, Pinter ME, Wright FA, Chan P, Murphy AJ, Valenzuela DM, Yancopoulos GD, Tall GG (2011) Ric-8 proteins are molecular chaperones that direct nascent $G$ protein alpha subunit membrane association. Sci Signal 4:ra79.
Graus-Porta D, Blaess S, Senften M, Littlewood-Evans A, Damsky C, Huang Z, Orban P, Klein R, Schittny JC, Müller U (2001) Beta1-class integrins regulate the development of laminae and folia in the cerebral and cerebellar cortex. Neuron 31:367-379.

Hampoelz B, Hoeller O, Bowman SK, Dunican D, Knoblich JA (2005) Drosophila Ric-8 is essential for plasma-membrane localization of heterotrimeric G proteins. Nat Cell Biol 7:1099-1105.

Hoser M, Baader SL, Bösl MR, Ihmer A, Wegner M, Sock E (2007) Prolonged glial expression of Sox 4 in the CNS leads to architectural cerebellar defects and ataxia. J Neurosci 27:5495-5505.

Huang Z, Shimazu K, Woo NH, Zang K, Müller U, Lu B, Reichardt LF (2006) Distinct roles of the beta 1-class integrins at the developing and the mature hippocampal excitatory synapse. J Neurosci 26:11208-11219.

Kinashi T (2005) Intracellular signalling controlling integrin activation in lymphocytes. Nat Rev Immunol 5:546-559.

Koirala S, Jin Z, Piao X, Corfas G (2009) GPR56-regulated granule cell adhesion is essential for rostral cerebellar development. J Neurosci 29:7439-7449.

Le Y, Zhu BM, Harley B, Park SY, Kobayashi T, Manis JP, Luo HR, Yoshimura A, Hennighausen L, Silberstein LE (2007) SOCS3 protein developmentally regulates the chemokine receptor CXCR4-FAK signaling pathway during B lymphopoiesis. Immunity 27:811-823.

Lein ES, Hawrylycz MJ, Ao N, Ayres M, Bensinger A, Bernard A, Boe AF, Boguski MS, Brockway KS, Byrnes EJ, Chen L, Chen L, Chen TM, Chin MC, Chong J, Crook BE, Czaplinska A, Dang CN, Datta S, Dee NR, et al. (2007) Genome-wide atlas of gene expression in the adult mouse brain. Nature 445:168-176.

Lewis PM, Gritli-Linde A, Smeyne R, Kottmann A, McMahon AP (2004) Sonic hedgehog signaling is required for expansion of granule neuron precursors and patterning of the mouse cerebellum. Dev Biol 270:393410.

Li G, Adesnik H, Li J, Long J, Nicoll RA, Rubenstein JL, Pleasure SJ (2008) Regional distribution of cortical interneurons and development of inhibitory tone are regulated by Cxcl12/Cxcr4 signaling. J Neurosci 28:10851098.

López-Bendito G, Sánchez-Alcañiz JA, Pla R, Borrell V, Pic ó E, Valdeolmillos M, Marín O (2008) Chemokine signaling controls intracortical migration and final distribution of GABAergic interneurons. J Neurosci 28: 1613-1624.

Machold R, Fishell G (2005) Math1 is expressed in temporally discrete pools of cerebellar rhombic-lip neural progenitors. Neuron 48:17-24.

Malatesta P, Hack MA, Hartfuss E, Kettenmann H, Klinkert W, Kirchhoff F, Götz M (2003) Neuronal or glial progeny: regional differences in radial glia fate. Neuron 37:751-764

Malbon CC (2005) G proteins in development. Nat Rev Mol Cell Biol 6:689-701.

Marinissen MJ, Gutkind JS (2001) G-protein-coupled receptors and signaling networks: emerging paradigms. Trends Pharmacol Sci 22:368-376.

Millen KJ, Gleeson JG (2008) Cerebellar development and disease. Curr Opin Neurobiol 18:12-19.

Miller KG, Emerson MD, McManus JR, Rand JB (2000) RIC-8 (Synembryn): a novel conserved protein that is required for $\mathrm{G}(\mathrm{q})$ alpha signaling in the C. elegans nervous system. Neuron 27:289-299.

Mills J, Niewmierzycka A, Oloumi A, Rico B, St-Arnaud R, Mackenzie IR, Mawji NM, Wilson J, Reichardt LF, Dedhar S (2006) Critical role of integrin-linked kinase in granule cell precursor proliferation and cerebellar development. J Neurosci 26:830-840.

Muzumdar MD, Tasic B, Miyamichi K, Li L, Luo L (2007) A global doublefluorescent Cre reporter mouse. Genesis 45:593-605.

Polizio AH, Chinchilla P, Chen X, Kim S, Manning DR, Riobo NA (2011) Heterotrimeric Gi proteins link Hedgehog signaling to activation of Rho small GTPases to promote fibroblast migration. J Biol Chem 286:19589_ 19596.

Qiu Z, Cang Y, Goff SP (2010) Abl family tyrosine kinases are essential for basement membrane integrity and cortical lamination in the cerebellum. J Neurosci 30:14430-14439.

Qu Q, Smith FI (2005) Neuronal migration defects in cerebellum of the Largemyd mouse are associated with disruptions in Bergmann glia organization and delayed migration of granule neurons. Cerebellum 4:261270.

Satz JS, Barresi R, Durbeej M, Willer T, Turner A, Moore SA, Campbell KP 
(2008) Brain and eye malformations resembling Walker-Warburg syndrome are recapitulated in mice by dystroglycan deletion in the epiblast. J Neurosci 28:10567-10575.

Satz JS, Ostendorf AP, Hou S, Turner A, Kusano H, Lee JC, Turk R, Nguyen H, Ross-Barta SE, Westra S, Hoshi T, Moore SA, Campbell KP (2010) Distinct functions of glial and neuronal dystroglycan in the developing and adult mouse brain. J Neurosci 30:14560-14572.

Shamri R, Grabovsky V, Gauguet JM, Feigelson S, Manevich E, Kolanus W, Robinson MK, Staunton DE, von Andrian UH, Alon R (2005) Lymphocyte arrest requires instantaneous induction of an extended LFA-1 conformation mediated by endothelium-bound chemokines. Nat Immunol 6:497-506.

Sillitoe RV, Joyner AL (2007) Morphology, molecular codes, and circuitry produce the three-dimensional complexity of the cerebellum. Annu Rev Cell Dev Biol 23:549-577.

Sudarov A, Joyner AL (2007) Cerebellum morphogenesis: the foliation pattern is orchestrated by multi-cellular anchoring centers. Neural Dev 2:26.

Tall GG, Gilman AG (2005) Resistance to inhibitors of cholinesterase 8A catalyzes release of Galphai-GTP and nuclear mitotic apparatus protein (NuMA) from NuMA/LGN/Galphai-GDP complexes. Proc Natl Acad Sci U S A 102:16584-16589.

Tall GG, Krumins AM, Gilman AG (2003) Mammalian Ric-8A (synembryn) is a heterotrimeric Galpha protein guanine nucleotide exchange factor. J Biol Chem 278:8356-8362.

Thomas CJ, Tall GG, Adhikari A, Sprang SR (2008) Ric-8A catalyzes guanine nucleotide exchange on G alphail bound to the GPR/GoLoco exchange inhibitor AGS3. J Biol Chem 283:23150-23160.

Thomas CJ, Briknarov á K, Hilmer JK, Movahed N, Bothner B, Sumida JP, Tall GG, Sprang SR (2011) The nucleotide exchange factor Ric-8A is a chaperone for the conformationally dynamic nucleotide-free state of Galphail. PLoS One 6:e23197.

Tõnissoo T, Meier R, Talts K, Plaas M, Karis A (2003) Expression of ric-8 (synembryn) gene in the nervous system of developing and adult mouse. Gene Expr Patterns 3:591-594.

Tõnissoo T, Kõks S, Meier R, Raud S, Plaas M, Vasar E, Karis A (2006)
Heterozygous mice with Ric- 8 mutation exhibit impaired spatial memory and decreased anxiety. Behav Brain Res 167:42-48.

Tõnissoo T, Lulla S, Meier R, Saare M, Ruisu K, Pooga M, Karis A (2010) Nucleotide exchange factor RIC-8 is indispensable in mammalian early development. Dev Dyn 239:3404-3415.

Tronche F, Kellendonk C, Kretz O, Gass P, Anlag K, Orban PC, Bock R, Klein R, Schütz G (1999) Disruption of the glucocorticoid receptor gene in the nervous system results in reduced anxiety. Nat Genet 23:99-103.

Tsai HH, Frost E, To V, Robinson S, Ffrench-Constant C, Geertman R, Ransohoff RM, Miller RH (2002) The chemokine receptor CXCR2 controls positioning of oligodendrocyte precursors in developing spinal cord by arresting their migration. Cell 110:373-383.

Wallace VA (1999) Purkinje-cell-derived Sonic hedgehog regulates granule neuron precursor cell proliferation in the developing mouse cerebellum. Curr Biol 9:445-448.

Wang H, Ng KH, Qian H, Siderovski DP, Chia W, Yu F (2005) Ric-8 controls Drosophila neural progenitor asymmetric division by regulating heterotrimeric G proteins. Nat Cell Biol 7:1091-1098.

Wang L, Guo D, Xing B, Zhang JJ, Shu HB, Guo L, Huang XY (2011) Resistance to inhibitors of cholinesterase-8A (Ric-8A) is critical for growth factor receptor-induced actin cytoskeletal reorganization. J Biol Chem 286:31055-31061.

Wechsler-Reya RJ, Scott MP (1999) Control of neuronal precursor proliferation in the cerebellum by Sonic Hedgehog. Neuron 22:103-114.

Welker WI (1990) The significance of foliation and fissuration of cerebellar cortex. The cerebellar folium as a fundamental unit of sensorimotor integration. Arch Ital Biol 128:87-109.

Yopak KE, Lisney TJ, Collin SP, Montgomery JC (2007) Variation in brain organization and cerebellar foliation in chondrichthyans: sharks and holocephalans. Brain Behav Evol 69:280-300.

Yue Q, Groszer M, Gil JS, Berk AJ, Messing A, Wu H, Liu X (2005) PTEN deletion in Bergmann glia leads to premature differentiation and affects laminar organization. Development 132:3281-3291.

Zhuo L, Theis M, Alvarez-Maya I, Brenner M, Willecke K, Messing A (2001) hGFAP-cre transgenic mice for manipulation of glial and neuronal function in vivo. Genesis 31:85-94. 